\title{
Infrared Spectroscopic Characterization of Phosphate Binding at the Goethite-Water Interface
}

Ashour A. Ahmed ${ }^{1,2, *}$, Stella Gypser ${ }^{3}$, Peter Leinweber ${ }^{2,4}$, Dirk Freese ${ }^{3}$, Oliver Kühn ${ }^{1,2}$

${ }^{1}$ University of Rostock, Institute of Physics, Albert-Einstein-Str. 23-24, D-18059 Rostock, Germany

${ }^{2}$ University of Rostock, Department of Life, Light, and Matter (LLM), Albert-Einstein-Str. 25, D-18059

Rostock, Germany

${ }^{3}$ Brandenburg University of Technology Cottbus-Senftenberg, Chair of Soil Protection and Recultivation, Konrad-Wachsmann-Allee 6, 03046 Cottbus, Germany

${ }^{4}$ University of Rostock, Chair of Soil Science, Justus-von-Liebig-Weg 6, D-18059 Rostock, Germany

*Corresponding author: ashour.ahmed@uni-rostock.de 


\section{Abstract}

The interaction between phosphates and soil mineral surfaces, such as $\mathrm{Fe}$ - and $\mathrm{Al}-$ (oxyhydr)oxides, plays a crucial role in the $\mathrm{P}$ immobilization and thus its availability for plants. The reactions of phosphates with Fe-hydroxides and especially goethite have been studied extensively. But a molecular-level picture about the phosphate binding mechanism at the goethite-water interface is still lacking. Therefore, in the current contribution we have explored the molecular binding mechanism for the adsorbed phosphate at the goethite-water interface by performing sorption kinetics experiments for orthophosphate and characterizing the adsorbed species by FT-IR spectroscopy. In parallel, periodic DFT calculations have been performed to explore the interaction mechanism as well as to calculate the IR spectra for monodentate $(\mathbf{M})$ and bidentate $(\mathbf{B})$ orthophosphate complexes at two different goethite surface planes (010 and 100) in the presence of water. In general, our interaction energy results give evidence that the mono-protonated $\mathbf{B}$ phosphate complex is more favored to be formed at the goethite-water interface although the $\mathbf{M}$ motif could exist as a minor fraction. Moreover, it was found that water plays an important role in controlling the phosphate adsorption process at the goethite surfaces. The interfacial water molecules form $\mathrm{H}$-bonds (HBs) with the phosphate as well as with the goethite surface atoms. Further, some water molecules form covalent bonds with goethite Fe atoms while others dissociate at the surface to protons and hydroxyl groups. The present theoretical assignment of IR spectra introduces a benchmark for characterizing experimental IR data for the adsorbed $\mathrm{KH}_{2} \mathrm{PO}_{4}$ species at the goethite-water interface. In particular, IR spectra of the mono-protonated $(2 \mathrm{O}+1 \mathrm{Fe}) \mathbf{B}$ complex at the 010 goethite surface plane and the $\mathbf{M}$ complex at the 100 goethite surface plane were found to be consistent with the experimental data. In order to explore the role of different abundancies of surface planes and binding motifs, IR spectra obtained from weighted averages have been analyzed. Results confirmed the above conclusions drawn from interaction energy calculations.

Keywords: phosphate, goethite, infrared spectroscopy, molecular modeling, density functional theory 


\section{Introduction}

Phosphorus $(\mathrm{P})$ plays an important role in the environmental nutrient cycle. $\mathrm{P}$ is central to all forms of life and its efficient use in fertilizers is one of the conditions for providing food for a rapidly increasing human population. Facing the projected peak $\mathrm{P}$ scenario ${ }^{\left[{ }^{[1]}\right.}$ substantial research activities have been triggered to improve our knowledge towards a more efficient and sustainable use of $\mathrm{P}$ resources. ${ }^{[2,3]}$ One major factor playing a role in the $\mathrm{P}$ immobilization and, thus, efficiency is the interaction between phosphates and soil solid phase components. In general, phosphates bind strongly to soil mineral surfaces and here especially to Fe- and Al-(oxyhydr)oxides. ${ }^{[4]}$ The reactions of phosphates with Fe-hydroxides have been studied thoroughly. ${ }^{[5-10]}$ Major findings concerned the adsorption rate and kinetics of phosphate binding to soil Fe-particles, revealing a biphasic behavior with a fast-initial adsorption step followed by a slower reaction phase. ${ }^{[10-13]}$ During the transition from fast to slow adsorption phases, the formation of initial mononuclear complexes and the conversion to binuclear complexes, the competition with anions on the surface or precipitation events were assumed. ${ }^{[14]}$ Further, in early adsorption experiments with synthetic Fe- and Al-hydroxides, the formation of stable inner-sphere surface complexes on metal ions, and ligand exchange have been detected. ${ }^{[15,16]}$

Particularly, the mineral goethite received much attention and, thus, goethite surface properties are well characterized. This is primarily due to the fact that goethite is the most common ferric iron $\mathrm{Fe}(\mathrm{III})$ oxyhydroxide in soils and its reactivity couples to a wide range of environmental processes. Therefore, it is a frequently used mineral for experimental and theoretical investigations of phosphate-surface reactions. ${ }^{[11,17-20]}$

Fourier-Transform Infrared (FT-IR) spectroscopic measurements were widely used to investigate spectral features of dissolved phosphate species and those adsorbed on Fe-oxide surfaces. Characteristic mid-infrared bands from symmetric and antisymmetric $\mathrm{P}-\mathrm{O}(\mathrm{H})$ vibrations can be detected even at low phosphate concentrations and depend on the symmetry of the ion. ${ }^{[6,19,21,22]}$ Therefore, the coordination geometry concluded from the IR spectrum is a helpful tool to identify the phosphate binding mechanism to the mineral surfaces. However, Villalobos et al. ${ }^{[23]}$ and Kubicki et al. ${ }^{[17]}$ pointed out that FT-IR spectroscopy of phosphate adsorption on goethite has general limitations in predicting the bonding of surface complexes. This is due to the presence of different crystal faces for powdered goethite samples as well as several binding motifs for the complexes between phosphate and each goethite crystal face. This might lead to broad FT-IR bands and different assigned surface complexes. As a result, different opinions have been arisen regarding the assignment of the binding motifs (monodentate and/or bidentate) of phosphate to the goethite surface. TejedorTejedor and Anderson ${ }^{[22]}$ and also Luengo et al. ${ }^{[11]}$ described bidentate $P$ complexes as the predominant binding motifs at the goethite surface with varying protonation states. Persson et 
al. ${ }^{[19]}$ and Loring et al. ${ }^{[24]}$ interpreted their IR results by formation of a monodentate binding motif for phosphate at goethite. In view of this debate, combining molecular simulations and experimental work provides the only means for clarifying the above contradicting explanations to achieve a better understanding for the phosphate-goethite complexation process and the existing binding motifs.

The sorption/desorption processes of phosphate to/from soil minerals can be understood and the role of the sorptive surfaces elucidated by calculation of binding energies and other physical parameters. ${ }^{[25]}$ Kubicki and co-workers in several papers have addressed the binding of phosphates to mineral surfaces. The $\mathrm{pH}$ dependence of phosphate binding to goethite $(\alpha-\mathrm{FeOOH}$, modeled as a small cluster of two edge-sharing iron octahedral including a few explicit water molecules) has been described using density functional theory (DFT). ${ }^{[25]}$ Based on calculated IR spectra and reaction energies, ${ }^{[6]}$ it was concluded that the dominant form at low $\mathrm{pH}$ is a bi-protonated bidentate form, whereas at neutral $\mathrm{pH}$ a mono-protonated monodentate species is dominant. This tendency was confirmed in a study by Kubicki et al. ${ }^{[26]}$ where emphasis has been placed on the correlation with IR and EXAFS data. Moreover, DFT simulations with periodic boundary conditions (PBC) have been applied to study the phosphate adsorption on variety of goethite surface planes. Here, IR spectra were obtained for cluster models extracted from the PBC simulation box. ${ }^{[17]}$

Despite these studies, a systematic molecular-level picture of phosphate binding mechanism at goethite-water interface is still lacking. In particular, there are neither experimental nor systematic theoretical studies focusing on the overall phosphate-goethitewater interactions and the individual (phosphate-goethite, phosphate-water, and goethitewater) interactions for different goethite surface planes at a molecular-scale. Therefore, our main target in the current contribution is to explore the molecular binding mechanism for the adsorption of phosphate at the goethite surface in the presence of water. This will be achieved by carrying out sorption kinetics experiments for orthophosphate at the goethite surface followed by characterization of the adsorbed species by FT-IR spectroscopy. Moreover, PBCDFT calculations will be performed using the mixed Gaussian and plane wave approach. Specifically, the interaction mechanism for orthophosphate with two different goethite surface planes in the presence of water will be explored. Contributions of individual phosphategoethite, phosphate-water, and goethite-water interactions will be addressed. Further, the competition between phosphate, water, and the hydroxyl $\left(\mathrm{OH}^{-}\right)$group for adsorption sites will be investigated. Moreover, IR vibrational frequencies will be calculated for different phosphate-goethite complexes and the corresponding spectra will be assigned. 


\section{Methods}

\subsection{Experiment}

\subsubsection{Materials}

The synthetic and commercially available adsorbent used in this study was goethite (99\%, Alfa Aesar, Massachusetts, USA). The crystallinity and composition of the synthetic goethite was confirmed by X-ray diffraction analysis (Fig. S1 in the supplementary information (SI)) using an Empyrean powder diffractometer (PANalytical, Almelo, Netherlands) with Cu Ka radiation $(\lambda=0.15418 \mathrm{~nm})$. Diffraction data were recorded from $4.6^{\circ}$ to $84.9^{\circ} 2 \Theta$ with a stepsize of 0.0131 and a step time of $58.4 \mathrm{~s}$. Determination of the d-values of the diffraction pattern and verification of the calculated orthorhombic lattice parameter $(a=4.61 \AA, b=9.96 \AA$, and $c=3.02 \AA$ ) were performed by using an open access version of XPowder. ${ }^{[27]}$ The specific surface area of $17.2 \mathrm{~m}^{2} \mathrm{~g}^{-1}$ was determined with an Autosorb-1 (Quantachrome, Odelzhausen, Germany) using a five-point Brunauer-Emmett-Teller (BET)-measurement and nitrogen as adsorptive medium. $\mathrm{KH}_{2} \mathrm{PO}_{4}$ and $\mathrm{CaCl}_{2}$ (VWR Chemicals, Darmstadt, Germany) were of analytical grade.

\subsubsection{Adsorption kinetics}

Phosphate adsorption kinetics has been conducted at $\mathrm{pH} 6.3$ with 4 replicates by using batch experiments with a solid-solution ratio of $1: 20$. Here, $1.5 \mathrm{~g}$ of goethite and $30 \mathrm{ml}$ of a $\mathrm{KH}_{2} \mathrm{PO}_{4}-\mathrm{CaCl}_{2}$ solution were used. For adsorption, an initial phosphate concentration of 150 $\mu \mathrm{mol} \mathrm{I}{ }^{-1}$ was chosen to achieve a low and incomplete loading of the goethite surface according to adsorption capacities mentioned in previous studies. ${ }^{[11,12,20,28,29]}$ The adsorption reaction mixture was horizontally shaken at 150 revolutions/min (rpm). Through this reaction kinetics, the equilibrium phosphate concentrations in the solution have been determined at different reaction times $(2,6,24,48,168,336,672,1344$, and $2688 \mathrm{~h})$. Specifically, the adsorption mixtures have been centrifuged at the mentioned times for $15 \mathrm{~min}$ at $2000 \mathrm{rpm}$ and the clear supernatant was filtrated by using P-poor Whatman $5121 / 1$ filters to separate it from the goethite solid matter. The equilibrium phosphate concentration was measured by the method of Murphy and Riley. ${ }^{[30]}$ Here, the amount of phosphate loss from solution was assumed to be completely adsorbed by the mineral phase.

\subsubsection{Fourier transform infrared (FT-IR) spectroscopy}

For FT-IR spectroscopic measurements, phosphate-goethite-suspensions at $2688 \mathrm{~h}$ reaction time have been centrifuged and the obtained solid samples were taken for the analysis. These samples were dried for $24 \mathrm{~h}$ at $40^{\circ} \mathrm{C}$ and stored in a desiccator and analyzed without further treatment prior to IR spectroscopic measurements. IR spectroscopic analyses 
were carried out by measurement of the absorbance in the FT-IR Drift mode (Tensor 27 HTSXT, Bruker, Massachusetts, USA) with 40 scans per sample, a wavenumber range from 400 to $4000 \mathrm{~cm}^{-1}$, and a resolution of $1.9 \mathrm{~cm}^{-1}$. For evaluation, all spectra together were truncated in the range 800 to $1300 \mathrm{~cm}^{-1}$, normalized with respect to the highest absorbance and the goethite spectrum was subtracted from the absorption spectra by using the software Essential FTIR® (Operant LLC, Virginia, USA).

\subsection{Theory}

\subsubsection{Molecular modeling}

We have considered two different goethite surface planes (010 and 100 according to the Pnma space group). These two goethite surface planes have been selected due to the stability of the 010 surface $^{[31,32]}$ and the abundance of the 100 surface plane ${ }^{[33-37]}$. The selected surface planes exhibit two kinds of $\mathrm{Fe}$ atoms with two different coordination numbers. For the bare 010 and 100 goethite surface planes, each surface Fe atom is coordinated by four and five $\mathrm{O}$ atoms, respectively. Therefore, this will give us the opportunity to explore different binding motifs between phosphate and goethite. These two surfaces have been modelled by periodic slabs, constructed by repetition of the goethite unit cell ${ }^{[38]}$ in the relevant directions (see Fig. 1a-d). The goethite orthorhombic unit cell used in the current contribution consists of four $\mathrm{FeOOH}$ formula units (16 atoms) with lattice constants $a=9.9560 \AA, b=3.0215 \AA$, and $c=4.6080 \AA$. These lattice constants are almost the same as the values determined experimentally (see Fig. S1 in the Electronic Supporting Information (ESI)). To simulate these surfaces, a layer of about $20 \AA$ vacuum was added between the periodic slabs perpendicular to the surface plane. In the vacuum region, phosphate was added at the top of each surface plane in two different starting configurations to construct monodentate $(\mathbf{M})$ and bidentate $(\mathbf{B})$ binding motifs (see Fig. 1e-g). This has been done by constructing one covalent bond (for $\mathbf{M}$ motif) and two covalent bonds (for $\mathrm{B}$ motif) between the phosphate $\mathrm{O}$ atoms and the goethite Fe atoms. The shortest distances between the adjacent Fe atoms are around $4.6 \AA$ for the 010 goethite surface plane and $3.0 \AA$ for the 100 surface plane. Therefore, the formation of the $\mathbf{B}$ binding motif between phosphate and the surface will mainly take place between two phosphate $\mathrm{O}$ atoms and one surface $\mathrm{Fe}$ atom $(2 \mathrm{O}+1 \mathrm{Fe})$ for the 010 surface plane (B@010) and two phosphate $\mathrm{O}$ atoms and two surface $\mathrm{Fe}$ atoms $(2 \mathrm{O}+2 \mathrm{Fe})$ for the 100 surface plane (B@100). ${ }^{[39]}$ To mimic the soil solution and its impact on the phosphate-goethite interaction, water molecules at a density of about $1 \mathrm{~g} / \mathrm{cm}^{3}$ have been introduced into the vacuum region between the slabs to construct the final simulation box (for example, see Fig. $1 \mathrm{~h}$, which contains $\alpha-\mathrm{FeOOH}$ (256 atoms) +1 phosphate molecule +150 water molecules $=714$ atoms) . Note that in contrast to previous work, ${ }^{[17]}$ the present simulation box is considerably larger, thus giving results less influenced by finite size effects. The solvation procedure involved filling 
the box vacuum region with water molecules by using the solvation tool provided by the Packmol software. ${ }^{[40]}$ To model the relevant $\mathrm{pH}$ solution to the present sorption experiment, the phosphate molecule has been introduced to the surface in the form of the $\mathrm{KH}_{2} \mathrm{PO}_{4}$ species. Therefore, we have 4 phosphate-goethite-water model systems, i.e. M@010, (2O+1Fe) B@010, M@100, and (2O+2Fe) B@100.

a)

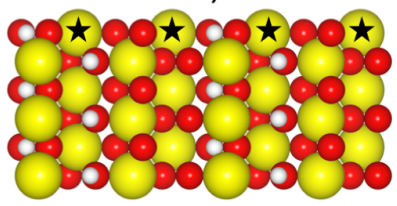

c)

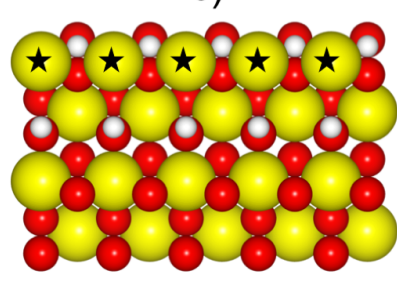

b)

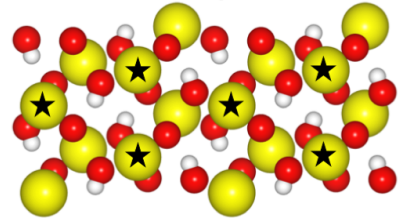

d)

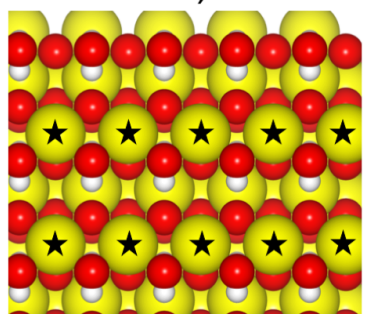

e)

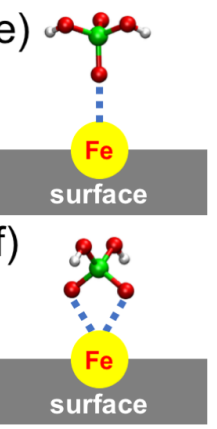

g)

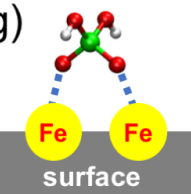

h)

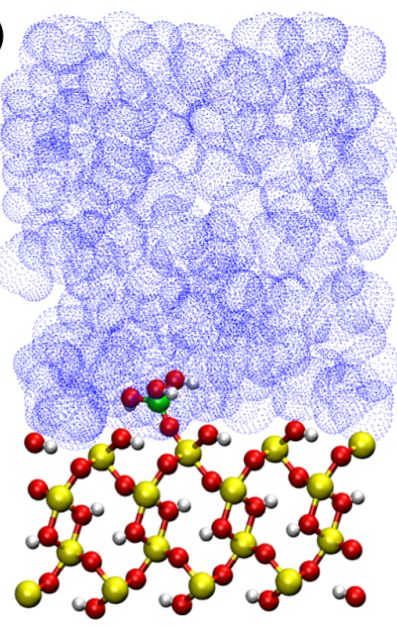

Fig. 1. Side and top views for the 010 goethite surface planes a) and b) as well as for the 100 goethite surface planes c) and d) according to the Pnma space group, schematic view for the possible binding motifs (M@010 and M@100 e), (2O+1Fe) B@010 f), (2O+2Fe) B@100 g)), and phosphate-goethite(100)-water model (h). White, red, green, and yellow colors are corresponding to $\mathrm{H}, \mathrm{O}, \mathrm{P}$, and Fe atoms, respectively. Atoms labeled by a star refer to the surface $\mathrm{Fe}$ atoms. Water molecules in Fig. $1 \mathrm{~h}$ are represented by blue spheres for better visualization.

Moreover, interaction of individual molecules (phosphate, water, and the $\mathrm{OH}^{-}$group) with the goethite surface in vacuum has been simulated as well. Here, three models have been built for each goethite surface plane (010 and 100). The first model involved complexation of a single $\mathrm{KH}_{2} \mathrm{PO}_{4}$ molecule at the goethite surface. The second model considers complexation of a single $\mathrm{H}_{2} \mathrm{O}$ molecule at the goethite surface. The third model involved complexation of a single $\mathrm{OH}^{-}$group in the presence of $\mathrm{K}^{+}$as counter ion at the goethite surface. All these complexes have been constructed in vacuum without adding solvent water molecules into the simulation box. For each case, the single fragment $\left(\mathrm{KH}_{2} \mathrm{PO}_{4}\right.$, $\mathrm{H}_{2} \mathrm{O}$, or $\mathrm{OH}^{-}$) was complexed to the goethite surface in a form of $\mathbf{M}$ binding motif. The aim of introducing these models is to investigate (1) the role of the aqueous solution in the phosphate-goethite binding process, (2) the competition among phosphate, water, and the $\mathrm{OH}^{-}$group regarding their interaction with the goethite surface, and (3) the $\mathrm{pH}$ effect on the phosphate-goethite binding process.

\subsubsection{Computational details}


For all the phosphate-goethite models in water as well as in vacuum, DFT-based geometry optimization has been carried out using the quickstep code ${ }^{[41]}$ implemented in the CP2K simulation package. ${ }^{[42]}$ Here, the hybrid Gaussian and plane-wave (GPW) method ${ }^{[43]}$ has been applied for calculating the DFT electronic ground state structure. The PerdewBurke-Ernzerhof (PBE) functional ${ }^{[44]}$ has been used together with the Goedecker-TeterHutter (GTH) pseudopotentials ${ }^{[45]}$. The electronic density cutoff for atomic core electrons was chosen as 500 Ry. The double- $\zeta$ valence polarized (DZVP) basis set optimized for the GTH pseudopotentials has been used. ${ }^{[46]}$ The empirical dispersion correction by Grimme "D3" was employed. ${ }^{[47]}$ PBC have been applied in all three spatial directions. Here, the total electronic energy was converged with a convergence threshold for the self-consistent field energy of $10^{-}$ ${ }^{8}$ Hartree.

To characterize the complexation reaction, phosphate + goethite surface $\rightarrow$ phosphategoethite-complex, the interaction energy $\left(E_{i n t}\right)$ between the phosphate species and the goethite surface plane for all optimized complexes was calculated as follows (for more details see the ESI):

$E_{\text {int }}=E_{\text {phosphate-goethite-complex }}-\left(E_{\text {phosphate }}+E_{\text {goethite surface }}\right)$

where, $E_{\text {phosphate-goethite-complex }}, E_{\text {phosphate, }}$ and $E_{\text {goethite surface }}$ are the total electronic energies of the geometry optimized phosphate-goethite-complex, phosphate, and goethite surface, respectively. For all interaction energies, the effect of the basis set superposition error (BSSE) has been corrected using the counterpoise scheme. ${ }^{[48]}$

Moreover, at the same level of theory the IR vibrational frequencies and IR intensities have been calculated for the optimized phosphate-goethite complexes of M@010, B@010, M@100, and B@100. The vibrational frequencies have been scaled by a frequency scaling factor of $0.986 .{ }^{[49]}$ IR spectra presented below have been obtained by including a phenomenological Gaussian broadening of width $30 \mathrm{~cm}^{-1}$. The calculated spectra for the different phosphate-goethite complexes were normalized individually to unity. It is important to mention that these calculated spectra are corresponding to the overall spectra of the adsorbed phosphate at the goethite surfaces. This means that every spectrum includes molecular vibrations by the phosphate-goethite complex and the goethite surface itself. In order to quantify the contribution of the phosphates, normal mode displacements have been analyzed to generate spectra due to modes that are dominated by phosphate vibrations (i.e. phosphate-related spectra). 


\section{Results and discussion}

\subsection{Adsorption kinetics and FT-IR spectroscopy}

After $2 \mathrm{~h}$ adsorption time, the whole amount of phosphate in the solution was essentially completely adsorbed to the goethite surface yielding a phosphate surface coverage of 0.18 $\mu \mathrm{mol} \mathrm{m}{ }^{-2}$. Assuming a regular distribution of the adsorbed phosphate at the goethite surface, this reported surface coverage indicates that the average separation distance between the neighboring phosphate molecules is about $3-5 \mathrm{~nm}$. In general, there is no observation of a difference in the phosphate uptake for different reaction times. This is due to the low initial phosphate concentration in solution, competition of hydroxyl and phosphate ions for adsorption sites and the negatively charged oxide surface..$^{[8,50,51]}$

Regarding FT-IR spectroscopy, comparison of the position of P-O bands and the assignment of the adsorbed complex and its molecular symmetry are difficult due to shift of the peak position based on reaction conditions, sample treatment, adsorbed phosphate content, $\mathrm{pH}$, and/or moisture.$^{[6,19,22,52-54]}$ Due to that, the number and not the exact position of vibrations were recommended as a characteristics by Arai and Sparks. ${ }^{[6]}$ Previous studies advised an analysis of metal-phosphate complexes in the spectral region from 940 to 1200 $\mathrm{cm}^{-1}$ due to the expected position of the two $\alpha-\mathrm{FeOOH}$ absorption bands at 828 and $927 \mathrm{~cm}^{-1}$ in the goethite spectrum. ${ }^{[22,24]}$ However, the present analysis will focus on a wider spectroscopic range $\left(800-1300 \mathrm{~cm}^{-1}\right)$ for better correlation with theory below.

The overall FT-IR spectrum that contains the molecular vibrations of the goethite surface and phosphate-goethite complex is presented in Fig. 2a. This spectrum exhibited mainly three peaks at 827,927 , and $1132 \mathrm{~cm}^{-1}$ and one shoulder at $1050 \mathrm{~cm}^{-1}$ (see Table 1). If only the number of bands were included as described by Arai and Sparks ${ }^{[6]}$, a $C_{3 v}$ symmetry point group can be assumed for the phosphate-goethite complex based on the three main bands. Referring to the dissolved phosphate species $^{[6]}$ and reference phosphate complexes ${ }^{[55]}$ included in Table 1 that have $\mathrm{C}_{3 \mathrm{v}}$ symmetry point groups, the observed vibrations in the present study could be assigned to be due to a monodentate complex. However, if the vibrational frequency at the shoulder is counted, a $C_{2 v}$ symmetry point group must be considered for the phosphate-goethite complex. For this case, bidentate phosphate-goethite complex could be assigned for the present experiment. This is mainly based on assignment of the dissolved phosphate species ${ }^{[6]}$ and reference phosphate complexes ${ }^{[55]}$ that have $C_{2 v}$ symmetry point groups (see Table 1). One should note that in another approach focusing on the position of P-O bands, Tejedor-Tejedor and Anderson ${ }^{[22]}$ assigned a non-protonated monodentate complex $\left(\mathrm{FePO}_{4}\right)$ at 1001 and $1025 \mathrm{~cm}^{-1}$, a non-protonated bidentate complex $\left(\mathrm{Fe}_{2} \mathrm{PO}_{4}\right)$ at 1044 and $1096 \mathrm{~cm}^{-1}$, and a mono-protonated bidentate complex $\left(\mathrm{Fe}_{2} \mathrm{HPO}_{4}\right)$ at 982, 1006 and $1123 \mathrm{~cm}^{-1}$ (see Table 1). According to this assignment, the present peak at $1132 \mathrm{~cm}^{-1}$ would be due to a mono-protonated bidentate phosphate-goethite complex 
$\left(\mathrm{Fe}_{2} \mathrm{HPO}_{4}\right)$. In addition, the shoulder at $1050 \mathrm{~cm}^{-1}$ could refer to the presence of a small proportion of non-protonated bidentate complex $\left(\mathrm{Fe}_{2} \mathrm{PO}_{4}\right)$ and/or mono-protonated monodentate complex $\left(\mathrm{FeHPO}_{4}\right)$. Moreover, the two pronounced peaks at 827 and $927 \mathrm{~cm}^{-1}$ could be due to molecular vibrations related to the goethite surface and not to the phosphategoethite complex as described before in the literature. ${ }^{[22,24]}$

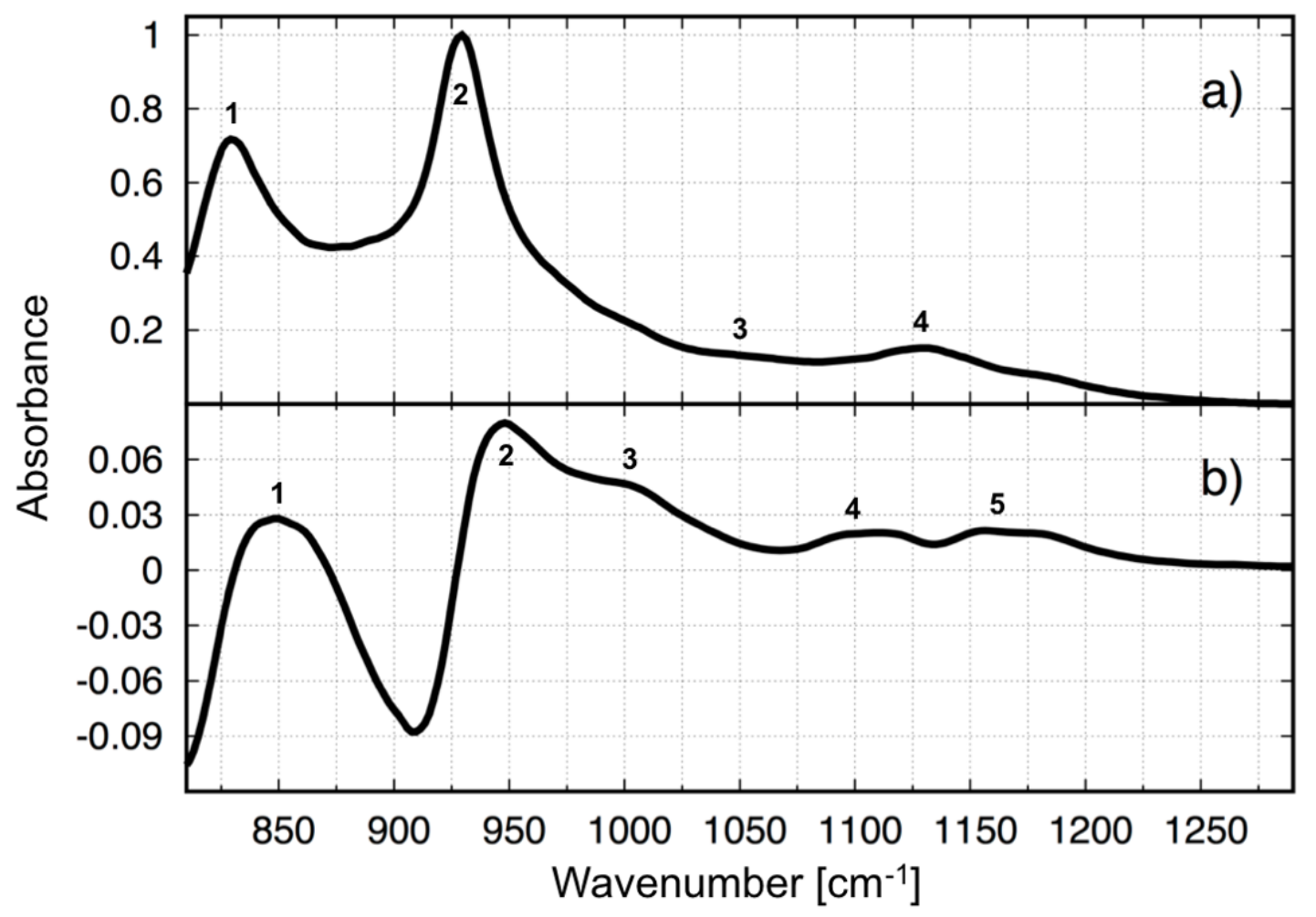

Fig. 2. Normalized overall experimental FT-IR spectrum of adsorbed phosphate on goethite surface at pH 6.3 after an adsorption time of $2688 \mathrm{~h}$ a) and the phosphate-related spectrum b) that was obtained by subtraction of the spectrum of pure goethite from the overall spectrum.

More information about the possible binding motifs for the phosphate-goethite complex is provided by interpretation of the difference IR spectrum relevant to the phosphate-goethite complex only (see Fig. 2b). In the following, we will call this spectrum as the phosphate-related spectrum. This spectrum was obtained by subtraction of the pure goethite spectrum from the overall spectrum. The phosphate-related spectrum exhibits four main spectral bands around $850,948,1110$, and $1165 \mathrm{~cm}^{-1}$ and one shoulder around $1000 \mathrm{~cm}^{-1}$ (see Table 1). The first two intense peaks around 850 and $948 \mathrm{~cm}^{-1}$ in this spectrum are similar to the observed ones for the overall spectrum (at 827 and $927 \mathrm{~cm}^{-1}$ ) but with a band position shift of about $25 \mathrm{~cm}^{-1}$. The presence of these two peaks in both spectra as well as the negative regions reveal that the phosphate-goethite complex could contribute to the observed spectral peaks in the overall spectrum. At the same time, there could be a strong coupling between goethite and phosphate motions. The observation of phosphate-related features in the range of $825-950 \mathrm{~cm}^{-1}$ comes in a good agreement with the reported spectral bands for Co-phosphate ${ }^{[55]}$ and phosphategoethite $^{[52]}$ complexes (see Table 1). 
In the following the analysis will focus on the three bands around 948, 1110, and 1165 $\mathrm{cm}^{-1}$ and the shoulder around $1000 \mathrm{~cm}^{-1}$, which are clearly related to the phosphate-goethite complex. A closer look at the phosphate-related spectrum shows the following: The observed band at $948 \mathrm{~cm}^{-1}$ is a narrow intense peak while the other bands are broad and less intense. The shoulder around $1000 \mathrm{~cm}^{-1}$ is distributed in the range of $990-1010 \mathrm{~cm}^{-1}$. The band around $1110 \mathrm{~cm}^{-1}$ is mainly distributed in the range of $1095-1120 \mathrm{~cm}^{-1}$ while the band around 1165 $\mathrm{cm}^{-1}$ corresponds to a bimodal peak with maxima located around 1156 and $1175 \mathrm{~cm}^{-1}$.

According to the assignment by Arai and Sparks ${ }^{[6]}$, a $C_{2 v}$ symmetry would involve four bands due to a bidentate motif, whereas a $\mathrm{C}_{3 v}$ symmetry would lead to three bands only, which could results from a monodentate motif. Thus, for the present case this doesn't provide a clearcut assignment.

Comparing with the results by Tejedor-Tejedor and Anderson, ${ }^{[22]}$ the present peaks around 948 and $1165 \mathrm{~cm}^{-1}$ could not be clearly assigned. On the other hand, the observed vibrations in the present study around $1000 \mathrm{~cm}^{-1}$ (range: $990-1010 \mathrm{~cm}^{-1}$ ) could be assigned as mono-protonated bidentate complex $\left(\mathrm{Fe}_{2} \mathrm{HPO}_{4}\right)$ and/or non-protonated monodentate complex $\left(\mathrm{FePO}_{4}\right)$. Vibrations around $1110 \mathrm{~cm}^{-1}$ (range: $1095-1120 \mathrm{~cm}^{-1}$ ) could be assigned as non-protonated bidentate complex $\left(\mathrm{FePO}_{4}\right)$, and/or mono-protonated bidentate complex $\left(\mathrm{Fe}_{2} \mathrm{HPO}_{4}\right)$. Thus, considering the assignment of Tejedor-Tejedor and Anderson ${ }^{[22]}$, the present IR spectrum indicates to the presence of a mixture of monodentate and bidentate complexes with a majority of the mono-protonated bidentate complex.

In contrast, Krumina et al. ${ }^{[52]}$ assigned the vibrational peaks at 940-945, 1004-1012, 1042-1050, 1085-1094, and 1110-1128 cm $\mathrm{cm}^{-1}$ (see Table 1) at different pH values as a series of monodentate phosphate surface complexes in different protonation states. According to this assignment, the present vibrational bands might indicate a mono-protonated monodentate complex $\left(\mathrm{FeHPO}_{4}\right)$.

This discussion clearly shows the yet unsolved general problem of assignment of phosphate-goethite binding motifs to IR features. This is to some extent due to variations in experimental conditions, but also due to the fact that observed IR spectra will always reflect binding at different surface planes of the mineral particles at the same time. Therefore, in the following we will first discuss our simulation results for well-defined systems, which could serve as reference for assignment. Subsequently, it will be shown how mixing of spectra due to different motifs can improve agreement with experiment. 
Table 1. Experimental IR frequencies of dissolved phosphate species, reference phosphate complexes, adsorbed phosphate on goethite and present calculated vibrational frequencies (features of the IR spectra and other relevant vibrational frequencies) for the adsorbed $\mathrm{KH}_{2} \mathrm{PO}_{4}$ on goethite for the optimized complexes of M@010, B@010, M@100, and B@100. FePO $\mathrm{O}_{4}$ non-protonated monodentate, FeHPO 4 : mono-protonated monodentate, $\mathrm{Fe}_{2} \mathrm{PO}_{4}$ : non-protonated bidentate, $\mathrm{Fe}_{2} \mathrm{HPO}_{4}$ : mono-protonated bidentate.

\begin{tabular}{|c|c|c|c|c|c|c|c|c|c|}
\hline study & \multicolumn{2}{|c|}{$\begin{array}{l}\text { species and } \\
\text { description }\end{array}$} & \multicolumn{7}{|c|}{ wavenumber $\left[\mathrm{cm}^{-1}\right]$} \\
\hline \multicolumn{10}{|c|}{ dissolved phosphate species } \\
\hline \multirow{4}{*}{ ref. [6] } & \multicolumn{2}{|c|}{$\mathrm{PO}_{4}^{3-}\left(\mathrm{T}_{\mathrm{d}}\right)$} & & & 1006 & & & & \\
\hline & \multicolumn{2}{|c|}{$\mathrm{HPO}_{4}{ }^{2-}\left(\mathrm{C}_{3 \mathrm{v}}\right)$} & 850 & 989 & & & 1077 & & \\
\hline & \multicolumn{2}{|c|}{$\mathrm{H}_{2} \mathrm{PO}_{4}^{-}\left(\mathrm{C}_{2 \mathrm{v}}\right)$} & 870 & 940 & & & 1074 & & 1160 \\
\hline & \multicolumn{2}{|c|}{$\mathrm{H}_{3} \mathrm{PO}_{4}\left(\mathrm{C}_{3 \mathrm{v}}\right)$} & 888 & & 1006 & & & & 1179 \\
\hline \multicolumn{10}{|c|}{ reference phosphate complexes } \\
\hline \multirow{4}{*}{ ref. [55] } & \multicolumn{2}{|c|}{$\begin{array}{c}\mathrm{Co}\left(\mathrm{NH}_{3}\right)_{5} \mathrm{PO}_{4} \\
\left(\mathrm{C}_{3 \mathrm{v}} \& \text { monodentate }\right)\end{array}$} & & 934 & 980 & 1030 & & & \\
\hline & \multicolumn{2}{|c|}{$\begin{array}{c}\left(\mathrm{CH}_{3} \mathrm{O}\right) \mathrm{PO}_{3}{ }^{2-} \\
\left(\mathrm{C}_{3 \mathrm{v}} \& \text { monodentate }\right)\end{array}$} & 755 & & 975 & & & 1095 & \\
\hline & \multicolumn{2}{|c|}{$\begin{array}{c}\mathrm{Co}\left(\mathrm{NH}_{2} \mathrm{CH}_{2} \mathrm{CH}_{2} \mathrm{NH}_{2}\right) \mathrm{PO}_{4} \\
\left(\mathrm{C}_{2 \mathrm{v}} \text { \& bidentate }\right)\end{array}$} & & 900 & 915 & & 1050 & 1085 & \\
\hline & \multicolumn{2}{|c|}{$\begin{array}{c}\left(\mathrm{CH}_{3} \mathrm{O}\right)_{2} \mathrm{PO}_{2}^{-} \\
\left(\mathrm{C}_{2 v} \text { \&bidentate }\right) \\
\end{array}$} & 815 & & & & 1050 & 1110 & 1220 \\
\hline \multicolumn{10}{|c|}{ phosphate-goethite complexes } \\
\hline \multirow{5}{*}{ ref. [22] } & \multicolumn{2}{|c|}{$150 \mu \mathrm{mol} \mathrm{I}^{-1} \mathrm{P}, \mathrm{pH} 5$} & & & 1006 & & 1043 & 1098 & 1123 \\
\hline & \multicolumn{2}{|c|}{$150 \mu \mathrm{mol} \mathrm{I}^{-1} \mathrm{P}, \mathrm{pH} 6$} & & & 1000 & 1023 & 1044 & 1099 & 1127 \\
\hline & & & & & 1001 & 1025 & & & \\
\hline & \multicolumn{3}{|c|}{$\mathrm{Fe}_{2} \mathrm{PO}_{4}$ and/or $\mathrm{FeHPO}_{4}$} & & & & 1044 & 1096 & \\
\hline & \multicolumn{2}{|c|}{$\mathrm{Fe}_{2} \mathrm{HPO} 4$} & & 982 & 1006 & & & & 1123 \\
\hline \multirow{3}{*}{ ref. [52] } & \multicolumn{2}{|c|}{$\mathrm{pH} 5$} & & 940 & 1010 & & 1042 & & 1120 \\
\hline & \multicolumn{2}{|c|}{$\mathrm{pH} 6$} & & 940 & 1004 & & 1050 & 1110 & \\
\hline & \multicolumn{2}{|c|}{$\mathrm{pH} 7$} & & 945 & & & 1050 & 1094 & \\
\hline \multirow{2}{*}{$\begin{array}{c}\text { present } \\
\text { experiment }\end{array}$} & \multicolumn{2}{|c|}{ overall spectrum } & 827 & 927 & & & 1050 & & 1132 \\
\hline & \multicolumn{2}{|c|}{$\begin{array}{c}\text { phosphate-related } \\
\text { spectrum }\end{array}$} & 850 & 948 & \multicolumn{2}{|c|}{$\begin{array}{c}1000 \\
(990-1010) \\
\end{array}$} & $\begin{array}{c}1110 \\
(1095-112 \\
\end{array}$ & $\begin{array}{r}11 \\
(11568 \\
\end{array}$ & 1175) \\
\hline \multirow{8}{*}{$\begin{array}{l}\text { present } \\
\text { theory }\end{array}$} & M @ 010 & features & 800 & 890 & 965 & 1035 & 1110 & & 1200 \\
\hline & & $\begin{array}{l}\text { other rele } \\
\text { frequencie }\end{array}$ & & 819 & 943 & 993 & 1049 & & \\
\hline & B @ 010 & features & 850 & & 970 & & 1122 & & 1223 \\
\hline & & $\begin{array}{l}\text { other rele } \\
\text { frequencie }\end{array}$ & & 830 & 923 & 954 & $992 \& 1007$ & $1035 \& 1069$ & 1107 \\
\hline & M @ 100 & features & 814 & 930 & & & 1050 & & 1171 \\
\hline & & $\begin{array}{l}\text { other rele } \\
\text { frequencie }\end{array}$ & & 838 & 853 & 945 & 957 & 999 & \\
\hline & B @ 100 & features & 830 & 890 & 950 & & 1048 & & 1137 \\
\hline & & $\begin{array}{l}\text { other reley } \\
\text { frequencie }\end{array}$ & & 826 & 829 & 862 & 930 & 974 & \\
\hline
\end{tabular}




\subsection{Structure and energetics of phosphate at the goethite-water interface}

Goethite bulk $\mathrm{Fe}$ atoms are saturated with octahedral coordination by $\mathrm{O}^{-2}$ and $\mathrm{OH}^{-}$in a $\mathrm{FeO}_{3}(\mathrm{OH})_{3}$ structure while $\mathrm{Fe}$ atoms of the neutral bare goethite surfaces are unsaturated and surface plane dependent. Hence, the goethite surface plane plays an important role in controlling the mechanism and strength of the reaction of phosphate with the goethite surface. To unravel this role, we will discuss our results with respect to the interaction of phosphate with the 010 and 100 goethite surface planes. Both surfaces may exhibit similar $\mathbf{M}$ binding motifs, but different $\mathbf{B}$ binding motifs with phosphates.

\subsubsection{Phosphate binding @ the 010 goethite surface plane}

For the most abundant phosphate species in the present experimental study $\left(\mathrm{KH}_{2} \mathrm{PO}_{4}\right)$, stable M (see Fig. 3a) and 2O+1Fe B (Fig. 3b) complexes are formed between phosphate and the goethite surface. The length of the Fe-O covalent bond for the $\mathbf{M}$ complex $(1.94 \AA)$ is shorter than for the $\mathbf{B}$ complex $(1.98 \& 2.03 \AA$, see Table 2$)$. These two complexes have a high interaction energy between phosphate and goethite (see Table 2) with the $\mathbf{B}$ complex being more stable than the $\mathbf{M}$ complex.

Regarding the phosphate-water interaction, one proton $\left(\mathrm{H}^{+}\right)$transfers from phosphate to water for both $\mathbf{M}$ and $\mathbf{B}$ complexes. This transferred proton stays in contact with its original phosphate donating $\mathrm{O}$ atom via formation of a $\mathrm{H}$-bond (HB). In contrast, the second proton in the $\mathrm{H}_{2} \mathrm{PO}_{4}{ }^{-}$species remained bonded to its phosphate $\mathrm{O}$ atom. In addition, other HBs between water $\mathrm{H}$ atoms and phosphate $\mathrm{O}$ atoms can be observed.

Regarding the water-goethite interaction, the surrounding water molecules approach the goethite surface and form covalent bonds with goethite. Mainly this takes place between water $\mathrm{O}$ atoms $\left(\mathrm{O}_{\mathrm{H}_{2} \mathrm{O}}\right)$ and most of the Fe active sites at the 010 goethite surface plane. The $\mathrm{Fe}-\mathrm{O}_{\mathrm{H}_{2} \mathrm{O}}$ covalent bond lengths are in the range of 1.87-2.06 $\AA$. Further, some of these water molecules dissociate at the goethite surface to protons $\left(\mathrm{H}^{+}\right)$and hydroxyl groups $\left(\mathrm{OH}^{-}\right)$. Regardless of these covalent bonds formed at the surface, water through its $\mathrm{H}$ atoms forms HBs with the goethite surface $O$ atoms.

Table 2. Interaction energies between phosphate $\left(\mathrm{KH}_{2} \mathrm{PO}_{4}\right)$ and goethite as well as selected distances for the optimized complexes of M@010, B@010, M@100, and B@100.

\begin{tabular}{llllll}
\hline \multirow{2}{*}{$\begin{array}{l}\text { surface } \\
\text { plane }\end{array}$} & \multirow{2}{*}{ binding motif } & \multirow{2}{*}{$\begin{array}{l}E_{\text {int }} \\
{\left[\mathrm{kcal} \mathrm{mol}^{-1}\right]}\end{array}$} & $\mathrm{Fe}_{\text {goethite }}-\mathrm{O}_{\mathrm{P}}$ & $\mathrm{Fe}-\mathrm{P}$ & $\mathrm{P}-\mathrm{O}_{\mathrm{P}}$ \\
\hline \multirow{2}{*}{$\mathbf{0 1 0}$} & $\mathbf{M}$ & -59 & 1.94 & 3.41 & $1.53,1.54,1.54,1.66$ \\
\cline { 2 - 6 } & $\mathbf{B ~ ( 2 O + 1 F e )}$ & -101 & $1.98 \& 2.03$ & 2.58 & $1.53,1.56,1.58,1.62$ \\
\hline \multirow{2}{*}{$\mathbf{1 0 0}$} & $\mathbf{M}$ & -74 & 2.12 & 3.48 & $1.55,1.56,1.58,1.58$ \\
\cline { 2 - 6 } & $\mathbf{B ~ ( 2 O + 2 F e )}$ & -102 & $1.95 \& 2.16$ & $3.15 \& 3.26$ & $1.51,1.57,1.59,1.61$ \\
\hline
\end{tabular}


a)
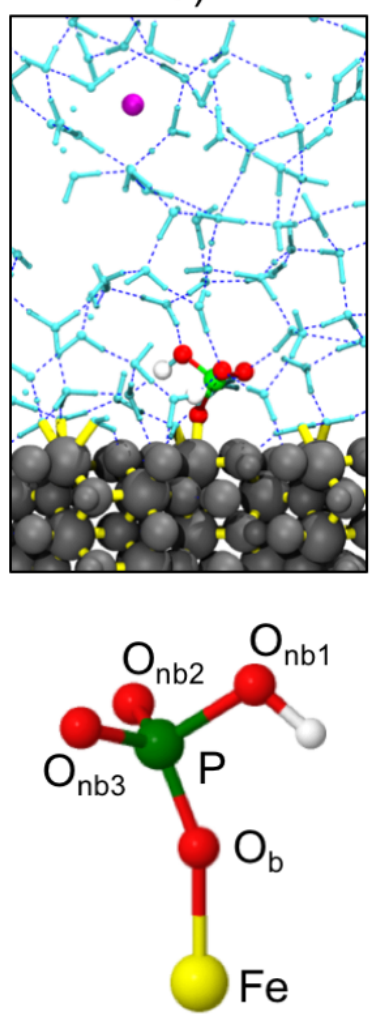

M@010 b)
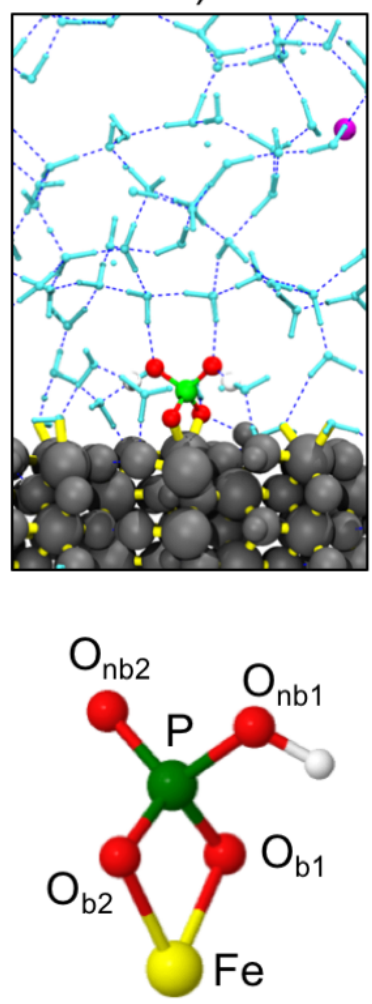

B @ 010 c)
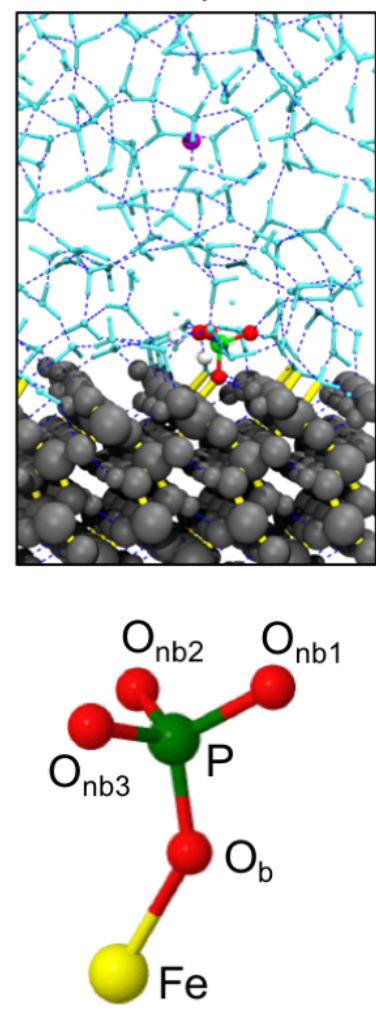

M@ 100 d)
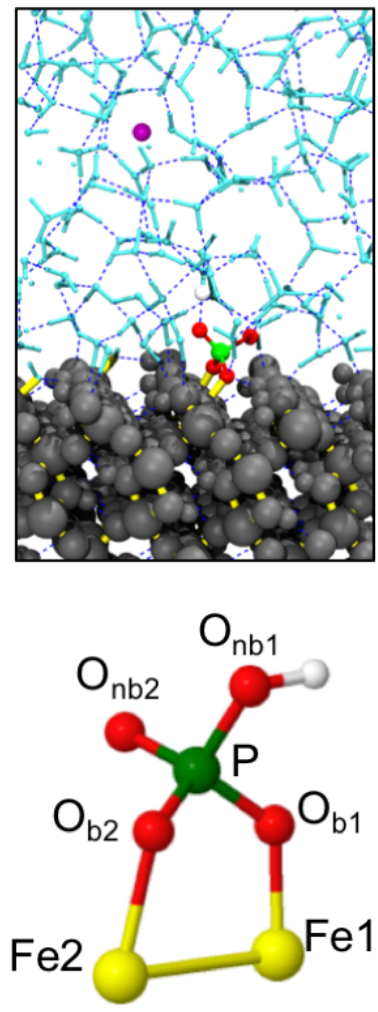

B@100

Fig. 3. Upper panel: Geometry optimized structures of the phosphate-goethite-water complexes for the M@010 motif (a), the (2O+1Fe) B@010 motif, M@100 motif (c), and (2O+2Fe) B@100 motif (d)). Goethite and water atoms are colored in gray and cyan, respectively. For phosphate, atoms are colored in green $(P)$, red $(O)$, white $(H)$, and purple (K). Intramolecular and intermolecular covalent bonds with goethite atoms are colored in yellow and HBs are colored in blue. Lower panel: Relevant fragments of the optimized binding motifs shown in the upper panel. Here $\mathrm{Fe}$ atoms are colored in yellow. $\mathrm{O}_{b}$ and $\mathrm{O}_{n b}$ refer to the bonded and non-bonded phosphate $\mathrm{O}$ atoms to the goethite surface Fe atoms.

For reference, let us discuss the interaction of the individual molecular systems (phosphate, water, and the $\mathrm{OH}^{-}$group) with the goethite surface in vacuum. The calculated interaction energies for the goethite complexes with $\mathrm{H}_{2} \mathrm{O}, \mathrm{KH}_{2} \mathrm{PO}_{4}$, and $\mathrm{KOH}$ are $-30,-83$, and $-162 \mathrm{kcal} \mathrm{mol}^{-1}$, respectively. This indicates that the strength of the adsorption process at the goethite surface increases in the order $\mathrm{H}_{2} \mathrm{O}<$ phosphate $<\mathrm{KOH}$. This means that phosphate can replace the adsorbed $\mathrm{H}_{2} \mathrm{O}$ molecules at the goethite surface. Moreover, at high $\mathrm{pH}$ and predominance of the $\mathrm{OH}^{-}$groups in the equilibrium solution, $\mathrm{OH}^{-}$can replace the adsorbed phosphate at the goethite surface yielding a strong drop in the phosphate adsorption. These findings agree with experimental results, such as by Liu et al. ${ }^{[56]}$ and Antelo et al. ${ }^{[57]}$, that reported a decrease of the phosphate adsorption with increasing the soil solution $\mathrm{pH}$. Moreover, these results indicate that water as an aqueous solution competes with the goethite surface regarding their binding to phosphate yielding less binding in the presence of water $\left(-59 \mathrm{kcal} \mathrm{mol}^{-1}\right)$ than in the vacuum case $\left(-83 \mathrm{kcal} \mathrm{mol}^{-1}\right)$. This points to the vital role of water and necessity of including water in molecular simulations as an aqueous solution for the phosphate-goethite binding process. 


\subsubsection{Phosphate binding @ the 100 goethite surface plane}

At the 100 goethite surface plane (Fig. 3c-d), the $\mathbf{B}$ complex is more stable than the $\mathbf{M}$ complex for the $\mathrm{H}_{2} \mathrm{PO}_{4}{ }^{-}$species (see Table 2). Consequently, this indicates that the $\mathbf{B}$ complex has a higher tendency to be formed. Furthermore, the $\mathbf{M @ 1 0 0 ~ c o m p l e x ~ i s ~ m o r e ~ s t a b l e ~ t h a n ~}$ the corresponding $\mathbf{M @ 0 1 0 ~ o n e . ~ I n ~ c o n t r a s t , ~ t h e ~ B ~ c o m p l e x e s ~ h a v e ~ a l m o s t ~ t h e ~ s a m e ~ s t a b i l i t y ~}$ at the 100 and 010 goethite surface planes.

For both complexes at the 100 goethite surface, the interfacial water molecules interact with the goethite surface via formation of covalent bonds between the water $\mathrm{O}_{\mathrm{H}_{2} \mathrm{O}}$ atoms and goethite Fe atoms. Moreover, $\mathrm{HBs}$ are formed between the water $\mathrm{H}_{\mathrm{H}_{2} \mathrm{O}}$ and the goethite $\mathrm{O}$ atoms. In addition, dissociation of some water molecules is observed at the surface to protons and hydroxyl groups. The thus produced ions form covalent bonds with the goethite surface. Moreover, for both $\mathbf{M}$ and $\mathbf{B}$ complexes, one proton transfers from phosphate to water (see Fig. 3c-d).

Similar to the 010 goethite surface case, the competition among phosphate, water, and the $\mathrm{OH}^{-}$group regarding their interaction with the 100 goethite surface plane has been studied in vacuum. The interaction energies for the goethite complexes with $\mathrm{H}_{2} \mathrm{O}, \mathrm{KH}_{2} \mathrm{PO}_{4}$, and $\mathrm{KOH}$ are $-22,-81$, and $-199 \mathrm{kcal} \mathrm{mol}^{-1}$, respectively. This means that the adsorption strength at the 100 goethite surface plane increases in the order $\mathrm{H}_{2} \mathrm{O}<$ phosphate $<\mathrm{KOH}$. This order is exactly the same as obtained in case of the 010 goethite surface plane. This order confirms again that phosphate has the ability to replace the adsorbed water molecules at the goethite surface but the $\mathrm{OH}^{-}$groups can replace both phosphate and water at the surface.

\subsubsection{Theory-experiment correlation}

The applied $\mathrm{pH}$ in the present experimental study suggests predominance of the $\mathrm{H}_{2} \mathrm{PO}_{4}{ }^{-}$ species. The calculated strength of the binding motifs of the $\mathrm{H}_{2} \mathrm{PO}_{4}{ }^{-}$species at both goethite surface planes increases in the order M@010 (-59 kcal mol $\left.{ }^{-1}\right)<\mathbf{M} @ 100\left(-74 \mathrm{kcal} \mathrm{mol}^{-1}\right)<$ 2O+1Fe B@010 (-101 kcal mol$\left.\left.{ }^{-1}\right) \approx 20+2 \mathrm{Fe} \mathrm{B@100} \mathrm{(-102} \mathrm{kcal} \mathrm{mol}{ }^{-1}\right)$, see Table 2. This reveals that both $\mathbf{B}$ motifs $(2 \mathrm{O}+1 \mathrm{Fe} \mathbf{B}$ and $2 \mathrm{O}+2 \mathrm{Fe} \mathbf{B})$ are the most abundant binding motifs at the studied surface planes for the used $\mathrm{pH}$ (i.e. in the presence of $\mathrm{H}_{2} \mathrm{PO}_{4}{ }^{-}$species). It is important to mention here that all these binding motifs observed in this case are monoprotonated motifs and also hydrogen-bonded to their original hydroxyl $\mathrm{H}$ atom. Thus, one can conclude that the mono-protonated $\mathbf{B}$ motif is the predominant binding motif at low phosphate loading and the experimentally studied $\mathrm{pH}$. Moreover, the mono-protonated $\mathbf{M}$ binding motif might exist but in a minor fraction. In principle, this is in agreement with an assignment of the present experimental IR spectrum according to Tejedor-Tejedor and Anderson ${ }^{[22]}$, i.e. to a mixture of minority monodentate and majority bidentate complexes. This assignment will be discussed in more detail in the following section. 


\subsection{Analysis of IR spectra}

All calculated IR spectra of the adsorbed phosphate species at the goethite surface for the different phosphate-goethite complexes are presented in Fig. 4. Here, the overall IR spectra due to molecular vibrations of the goethite surface and phosphate-goethite complexes as well as the phosphate-related IR spectra have been introduced.

For the M@010 binding motif, the overall IR spectrum in the range of $800-1300 \mathrm{~cm}^{-1}$ exhibits six features (four peaks and two shoulders) around 800, 890, 965, 1035, 1110, and $1200 \mathrm{~cm}^{-1}$ (see Fig. 4a). Comparing the overall spectrum to the corresponding phosphaterelated spectrum, one observes that not all features in this range originate from phosphate molecular vibrations. Figure $4 a$ shows that features 2 and 5 are due to goethite surface vibrations only. All other features in the $\mathbf{M @ 0 1 0 ~ s p e c t r u m ~ c o n t a i n ~ c o n t r i b u t i o n s ~ f r o m ~ t h e ~}$ phosphate-goethite complex and the goethite surface, although features 1 and 6 are dominated by phosphate vibrations. For the B@010 complex, Fig. 4b shows that the overall IR spectrum exhibits four features around $850,970,1122$, and $1223 \mathrm{~cm}^{-1}$. Here, phosphate vibrations are dominant for features 1 and 4 . Notice that shifts in the peak position can be observed when comparing both spectra.

At the 100 goethite surface plane, the overall spectrum for the $\mathbf{M}$ complex exhibits four features around 814, 930, 1050, and $1171 \mathrm{~cm}^{-1}$ (see Fig. 4c). Comparing the overall and the phosphate-related spectra, one notices that in this case the goethite vibrations give the dominant contribution to the spectrum in the whole range. For the B@100 complex, Fig. 4d shows that the overall spectrum exhibits five features around 830, 890, 950, 1048, and 1137 $\mathrm{cm}^{-1}$. Phosphate vibrations contribute strongly to all features except feature 5 . Feature 4 is solely due to phosphate modes. Feature 2 in the overall spectrum is reduced to a shoulder in the phosphate spectrum. The opposite holds true for feature 3.

Finally, we comment on the relative intensities of the different panels in Fig. 4. Specifically, intensities of the highest peaks for the different complexes have the order M@100 > B@100 > M@010 > B@010 with scaling factors of 1x $($ M@100 $)=7.4 x(B @ 100)=$ 9.2x $(\mathbf{M} @ 010)=9.9 x(B @ 010)$. In case of the phosphate-related spectra, intensities of the highest peaks have the order M@100 > B@100 > M@010 > B@010 with scaling factors of 1x $(\mathbf{M} @ 100)=1.7 x(B @ 100)=2.3 x(M @ 010)=2.4 x(B @ 010) . ~ T h u s$, under the assumptions of equal contributions to a measured spectrum, the M@100 complex would be clearly dominant, in terms of both, the overall and the phosphate-related IR spectra. 


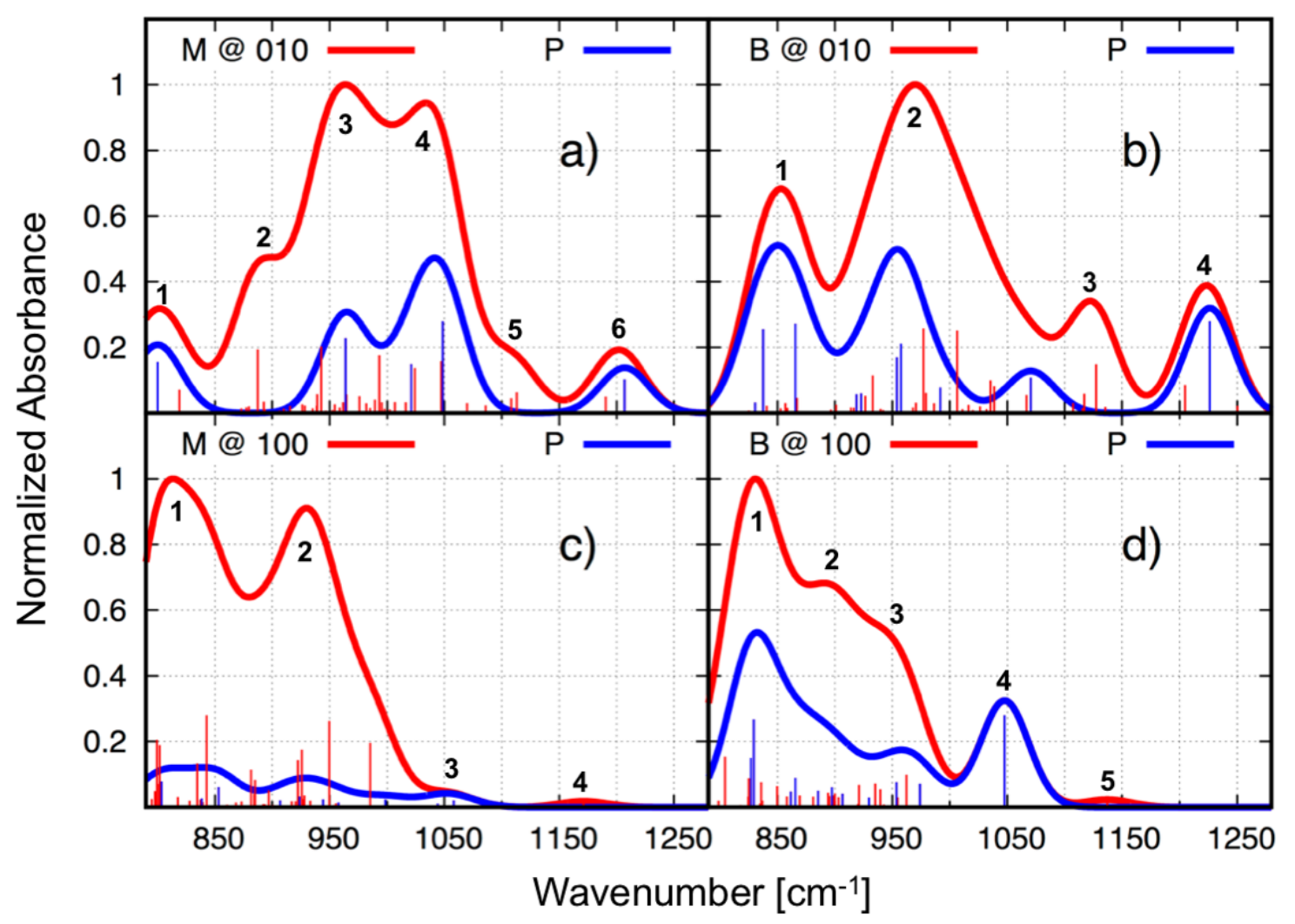

Fig. 4. Calculated IR spectra (sticks and phenomenologically broadened with half-width of $30 \mathrm{~cm}^{-1}$ ) of the adsorbed phosphate species $\left(\mathrm{KH}_{2} \mathrm{PO}_{4}\right)$ at the goethite surface for the optimized complexes of $\mathbf{M @ 0 1 0 ~ a ) , ~ B @ 0 1 0 ~ b ) , ~ M @ 1 0 0 ~}$ c), and B@100 d). Red color refers to the overall spectrum due to the goethite surface and the phosphate-goethite complexes while blue color refers to contributions of the phosphate-goethite complexes only (phosphate-related spectrum). 
Table 3. Assignment of the IR spectra calculated for the adsorbed $\mathrm{H}_{2} \mathrm{PO}_{4}{ }^{-}$on goethite for the optimized complexes of M@010 and B@010 binding motifs. Underlined frequencies refer to those vibrations having high phosphate contributions. $\mathrm{O}_{b}$ and $\mathrm{O}_{n b}$ refer to the bonded and non-bonded phosphate $\mathrm{O}$ atoms at the goethite surface. sym., asym., and str. are abbreviations for symmetric, antisymmetric, and stretching, respectively.

\begin{tabular}{|c|c|}
\hline $\begin{array}{l}\text { binding } \\
\text { motif }\end{array}$ & frequencies in $\mathrm{cm}^{-1}$ and their description \\
\hline 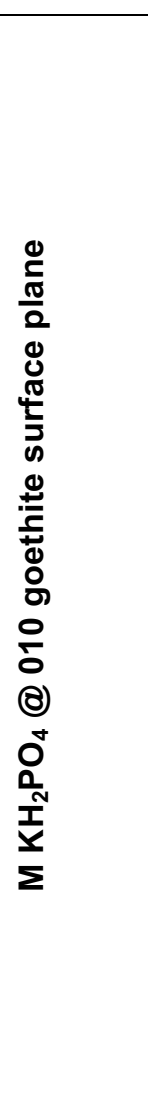 & 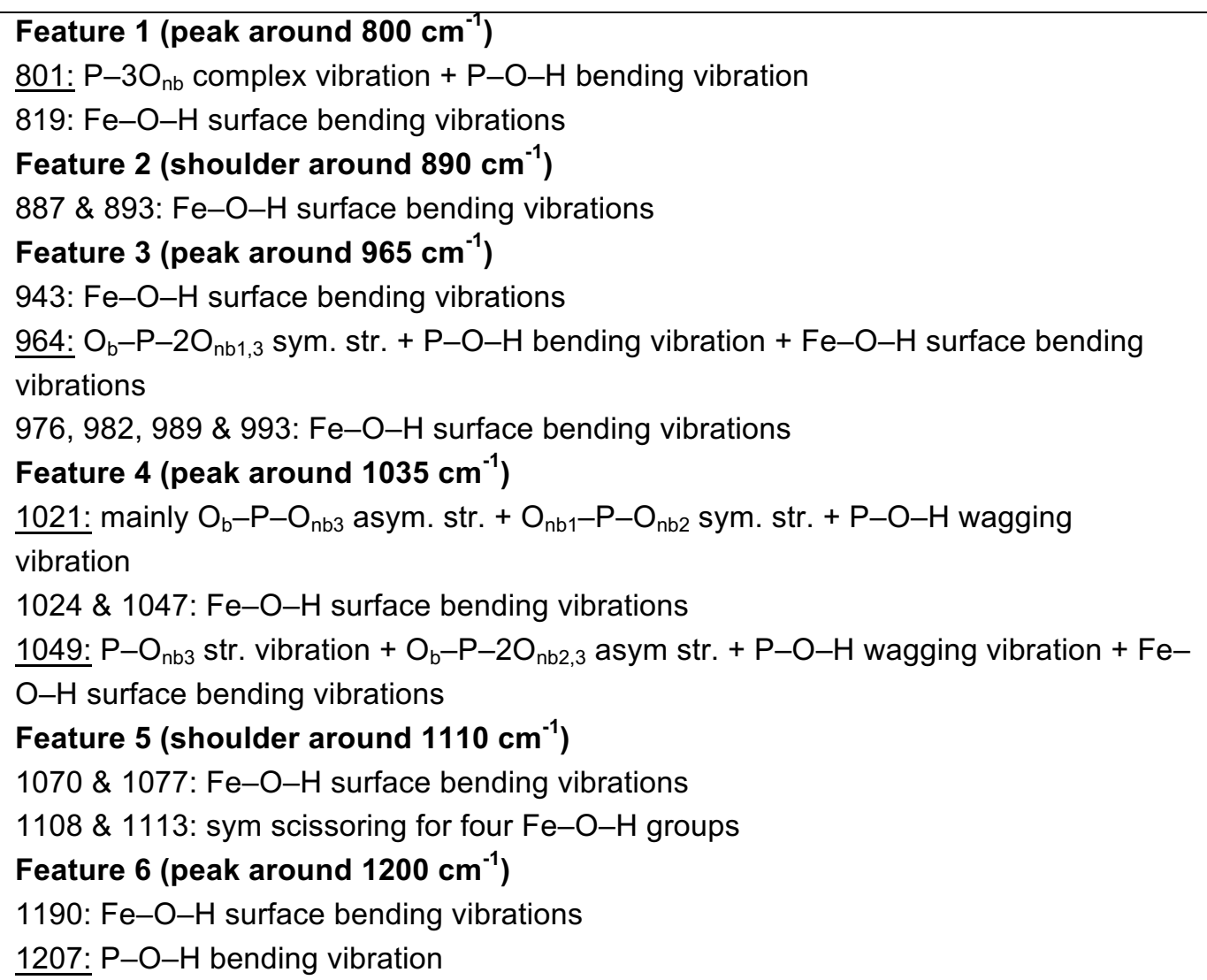 \\
\hline 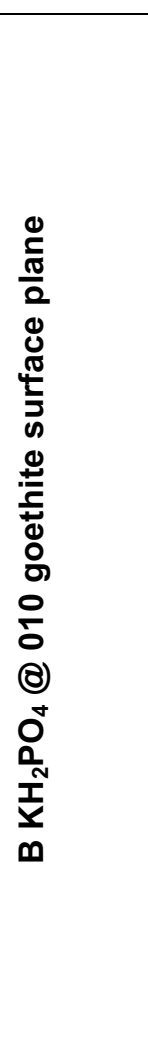 & 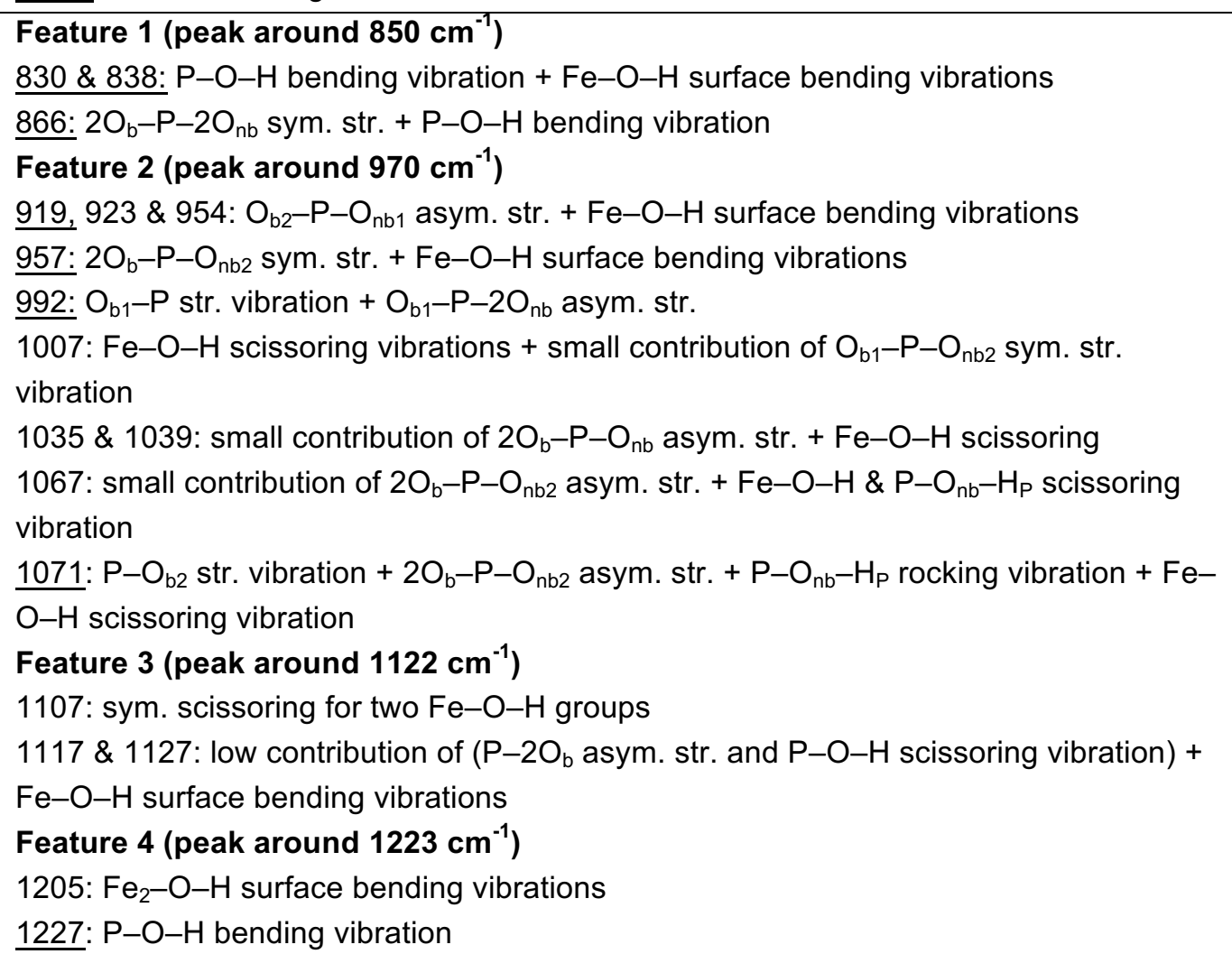 \\
\hline
\end{tabular}


Table 4. Assignment of the IR spectra calculated for the adsorbed $\mathrm{H}_{2} \mathrm{PO}_{4}{ }^{-}$on goethite for the optimized complexes of M@100 and B@100 binding motifs. Underlined frequencies refer to those vibrations having high phosphate contributions. $O_{b}$ and $O_{n b}$ refer to the bonded and non-bonded phosphate $O$ atoms at the goethite surface. sym., asym., and str. are abbreviations for symmetric, antisymmetric, and stretching, respectively.

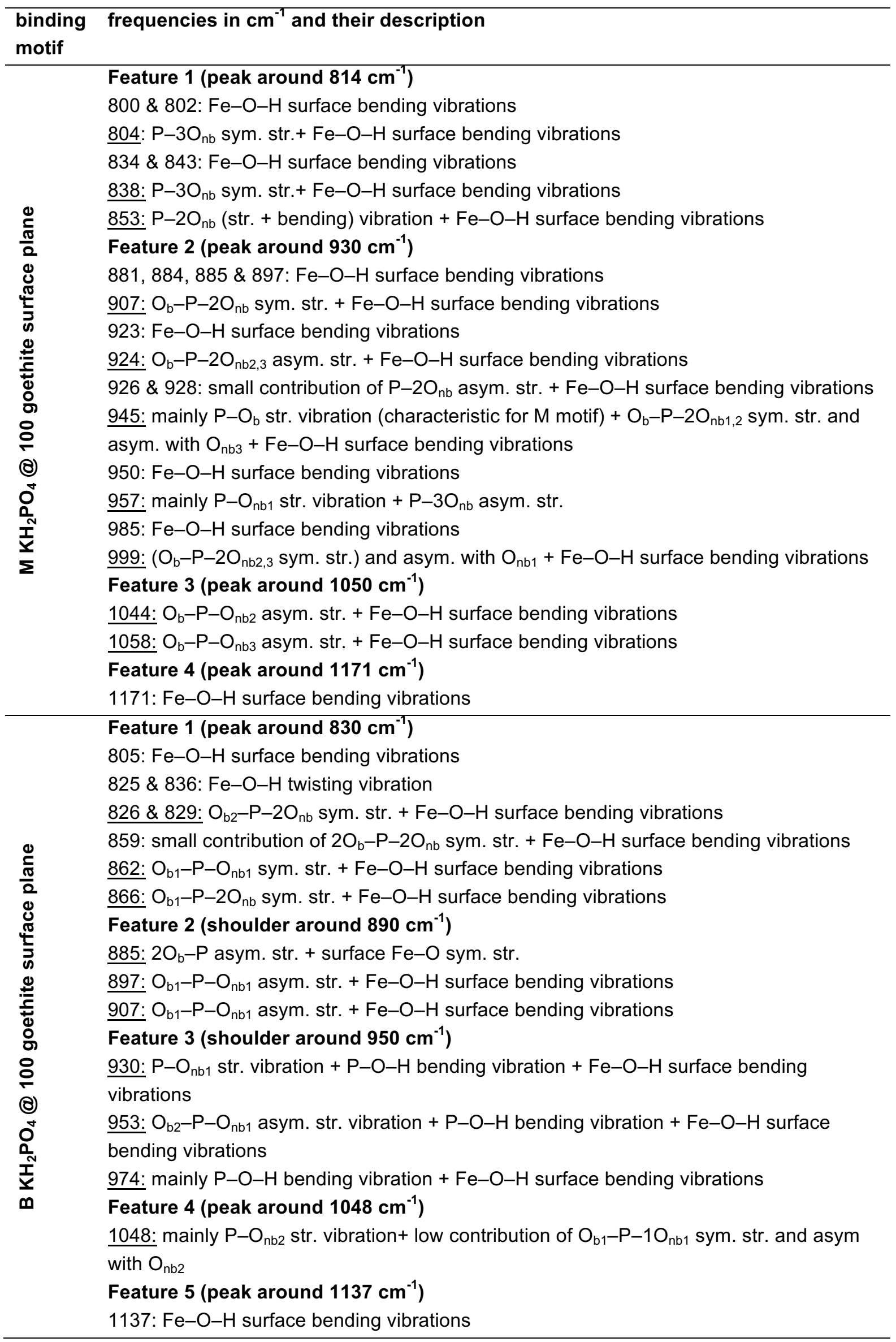


The assigment of the IR spectra for the different binding motifs is provided in Tables 3 and 4, see also definition of atom labels in Fig. 3. Overall, the calculated IR spectra and their assignment are strongly dependent on the binding motif type of the phosphate-goethite complex as well as the goethite crystal surface plane. It is important to emphasize that the experimental IR spectrum is due to a combination of all different binding motifs at the different surface planes (not only 010 and 100) present in the real sample. Further, the experimental IR measurements have been conducted for dried samples. Thus, a one-to-one comparison is rather difficult if not impossible. Therefore, below we will present a systematic study of the effect of varying composition on the IR spectral features. First, however, the assignment of the spectra for the different motifs will be discussed.

For the M@010 motif, vibrational frequencies related to phosphate and closest in the position to bands of the overall experimental IR spectrum are found at $819,943,1049$, and $1113 \mathrm{~cm}^{-1}$. All these frequencies except at $1049 \mathrm{~cm}^{-1}$ are mainly related to Fe-O-H surface bending vibrations. The mode at $1049 \mathrm{~cm}^{-1}$ is a combination of $\mathrm{P}-\mathrm{O}_{\mathrm{nb} 3}$ stretching, $\mathrm{O}_{\mathrm{b}}-\mathrm{P}-$ $2 \mathrm{O}_{\mathrm{nb} 2,3}$ asymmetric stretching, and $\mathrm{P}-\mathrm{O}-\mathrm{H}$ wagging vibrational motions. For the B@010 motif phosphate-related vibrations are found at $830,923,1039$, and $1127 \mathrm{~cm}^{-1}$. All these peaks are due to $\mathrm{Fe}-\mathrm{O}-\mathrm{H}$ surface bending vibrations in addition to different phosphate vibrations. The modes at 830 and $923 \mathrm{~cm}^{-1}$ have contributions from $\mathrm{P}-\mathrm{O}-\mathrm{H}$ bending and $\mathrm{O}_{\mathrm{b} 2}-\mathrm{P}-\mathrm{O}_{\mathrm{nb} 1}$ asymmetric stretching vibrations, respectively. The modes at 1039 and $1127 \mathrm{~cm}^{-1}$ have small contributions from $2 \mathrm{O}_{b}-\mathrm{P}-\mathrm{O}_{\mathrm{nb}}$ and $\mathrm{P}-2 \mathrm{O}_{b}$ asymmetric stretching vibrations, respectively. For the M@100 motif, relevant vibrational frequencies are found at 834, 928, 1044, 1058, and $1171 \mathrm{~cm}^{-1}$. The related modes are mainly composed of Fe-O-H surface bending vibrations, with contributions from $\mathrm{O}_{b}-\mathrm{P}-1 \mathrm{O}_{\mathrm{nb}}$ asymmetric stretching vibrations for the 1044 and 1058 $\mathrm{cm}^{-1}$ cases. For the B@100 motif, relevant vibrational frequencies are observed at 826, 829, 930,1048 , and $1137 \mathrm{~cm}^{-1}$, which mainly all involve $\mathrm{Fe}-\mathrm{O}-\mathrm{H}$ surface bending vibrations. An exception is the mode at $1048 \mathrm{~cm}^{-1}$ which is of $\mathrm{P}-\mathrm{O}_{\mathrm{nb} 2}$ stretching type. Also, the modes at 826 and $829 \mathrm{~cm}^{-1}$ have contributions from $\mathrm{O}_{\mathrm{b} 2}-\mathrm{P}-2 \mathrm{O}_{\mathrm{nb}}$ symmetric stretching vibrational motion. $\mathrm{P}-$ $\mathrm{O}_{\mathrm{nb} 1}$ stretching and $\mathrm{P}-\mathrm{O}-\mathrm{H}$ bending vibrations are participating in the modes at $930 \mathrm{~cm}^{-1}$.

Let us first compare the calculated phosphate-related IR spectra with the corresponding experimental IR spectrum (Fig. 2). The latter shows negative and positive features in the range below $900 \mathrm{~cm}^{-1}$, which could involve band shifts as discussed before. This hinders straightforward comparison, but one can state that all cases except $\mathbf{M} @ 010$ predict a strong phosphate-related band around $850 \mathrm{~cm}^{-1}$ (for more details, see ESI). The situation is more favourable if the focus is set on the spectral range of $925-1280 \mathrm{~cm}^{-1}$ (see Fig. 5). The overall behavior and in particular the dominant peak at $950 \mathrm{~cm}^{-1}$ is best reproduced by the B@010 and the M@100 complexes. The shoulder in the experimental spectrum at about $1000 \mathrm{~cm}^{-1}$ is seen in case of the M@100 complex. In addition, a qualitative agreement between the experimental spectrum and that for the B@010 complex can be found in the range of 1050- 
$1200 \mathrm{~cm}^{-1}$, i.e. in both cases one observes two bands. Up to this point, one could conclude an abundance of the B@010 and the M@100 complexes under the present experimental conditions.

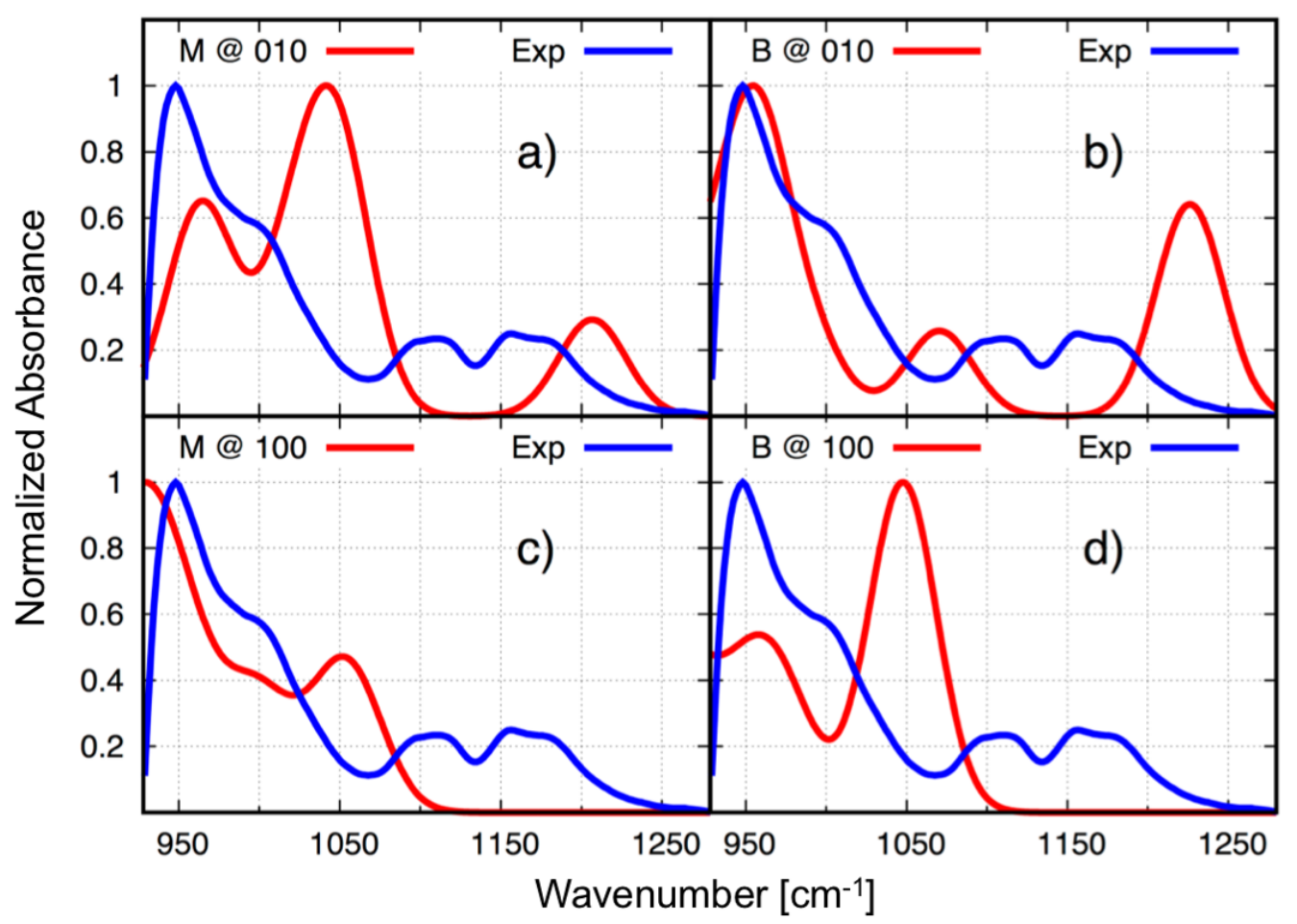

Fig. 5. Experimental IR difference spectrum relevant to the phosphate-goethite complex (in blue) versus the phosphate-related spectra calculated for the optimized complexes of M@010 a), B@010 b), M@100 c), and $B @ 100 \mathrm{~d}$ ) in the range of $925-1300 \mathrm{~cm}^{-1}$. Note that the spectra are individually normalized such that the maximum equals unity.

In order to use the information contained in the full spectral range and to also account for possible interaction-induced peak shifts, we will focus on the comparison of the overall experimental and theoretical spectra in the following. At first glance, the results in Fig. 6 indicate a reasonable agreement in particular for the M@100 and B@010 complexes. Here, the M@100 complex shows a better agreement with the experiment as far as the first two peaks are concerned. However, only for the B@010 complex spectral intensity beyond 1000 $\mathrm{cm}^{-1}$ is predicted. More specifically the experimental peak observed at $827 \mathrm{~cm}^{-1}$ could be evolved due to molecular vibrations related to the B@010, M@100, and/or B@100 complex(es), while that peak observed at $927 \mathrm{~cm}^{-1}$ could correspond to the M@010,B@010, and/or M@100 complex(es). Furthermore, the observed peak at $1132 \mathrm{~cm}^{-1}$ could be assigned as being due to the B@010 complex, whereas the shoulder at $1050 \mathrm{~cm}^{-1}$ could be assigned to the M@100 complex. Given the fact that experimental spectra will be affected by the presence of different crystal planes and therefore binding motifs, one might ask whether a weighted average of the present theoretical results would lead to an improved agreement with 
experiment. Of course, this neglects the possible presence of other crystal planes as well as effects due to, e.g., surface coverage and drying conditions.

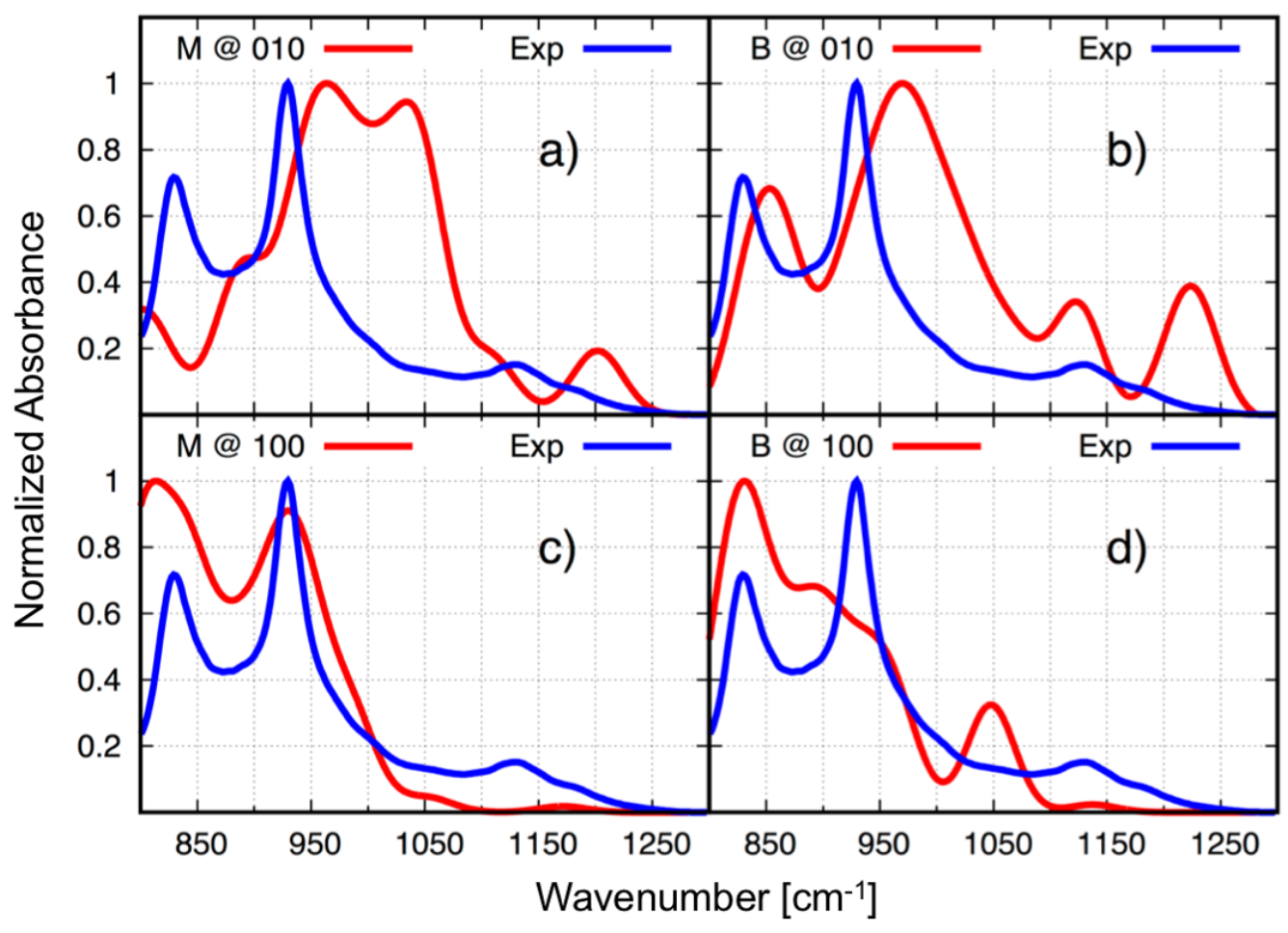

Fig. 6. Overall experimental IR spectrum (in blue) versus the calculated overall spectra (red) of the adsorbed phosphate species $\left(\mathrm{H}_{2} \mathrm{PO}_{4}{ }^{-}\right)$at the goethite surface for the optimized complexes of M@010 a), B@010 b), M@100 c), and B@100 d). Note that the spectra are individually normalized such that the maximum equals unity.

Calculated spectra obtained by weighted averaging are shown in Fig. 7 and compared with the overall experimental IR spectrum of the adsorbed phosphate at the goethite surface. For better comparison with Fig. 6 we have combined the normalized spectra. The respective mixing ratios taking into account the individual intensities will be given as well.

Figure 7a shows weighted average spectra that have proportions of M@010:B@010 varying from 1:9 to 9:1. (Taking into account the the peak intensity ratio $1 \times(\mathbf{M} @ 010)=$ 1.076(B@010) this corresponds to ratios from 1:9.7 to 1:0.12) The comparison with experiment clearly improves by decreasing the M@010:B@010 proportion from 9:1 to 1:9. Results for the respective M@100 and B@100 complexes are presented in Fig. 7b. Taking into account the the peak intensity ratio 1x $(\mathbf{M} @ 100)=7.4 \mathrm{x}(\mathrm{B} @ 100)$ this corresponds to ratios from $1: 66.6$ to $1: 0.8$. Here, the consistency with the experimental IR spectrum is enhanced with increasing the M@100 fraction. However, even the 9:1 fraction implies that upon accounting for the IR intensities, there is a high B@100 fraction (1:0.8) needed for good agreement with the experimental spectrum. Comparing panels $a$ and $b$, one notices that having high proportions of the M@100 complex is more consistent with the experimental data than having high proportions of the B@010 complex. An exception is the feature at $1132 \mathrm{~cm}^{-}$ 
${ }^{1}$ which appears only in the spectra of the $\mathbf{B} @ 010$ complex. This suggests to mix spectra of the B@010 and the M@100 complexes with different proportions. For this case, the spectra are weighted with proportions of M@100:B@010 changing again from 1:9 to 9:1 (given the intensity ratio 1x $(\mathbf{M} @ 100)=9.9 x(B @ 010)$ this corresponds to 1:89 to 1:1.1). The results in Fig. 7c show that having a sizeable M@100 fraction will improve the agreement with respect to the positions of the first two features. On the other hand, the contribution of the B@010 complex is required to obtain the feature observed around $1132 \mathrm{~cm}^{-1}$. Close inspection reveals that a ratio of M@100:B@010=7:3 (or after taking into account IR intensities 1:4.2) is most consistent with experiment. Eventually, we have also made an attempt to include all different binding motifs at both surface planes into the weighted averaging. Reasonable results have been obtained by selecting the combination of 5M@100+5B@100 with 1M@010+9B@010. Then we have mixed these two combinations with different proportions giving the results shown in Fig. $7 d$. Here, a good agreement is obtained for a ratio $7: 3$, corresponding to roughly 1M@100+1B@100+0.1M@010+0.8B@010, or if peak intensities are taken into account 1M@100+7B@100+1M@010+9B@010. In any case, the outlined procedure quantitatively demonstrates the sensitivity of the IR spectrum with respect to the fine details of the composition of the sample.

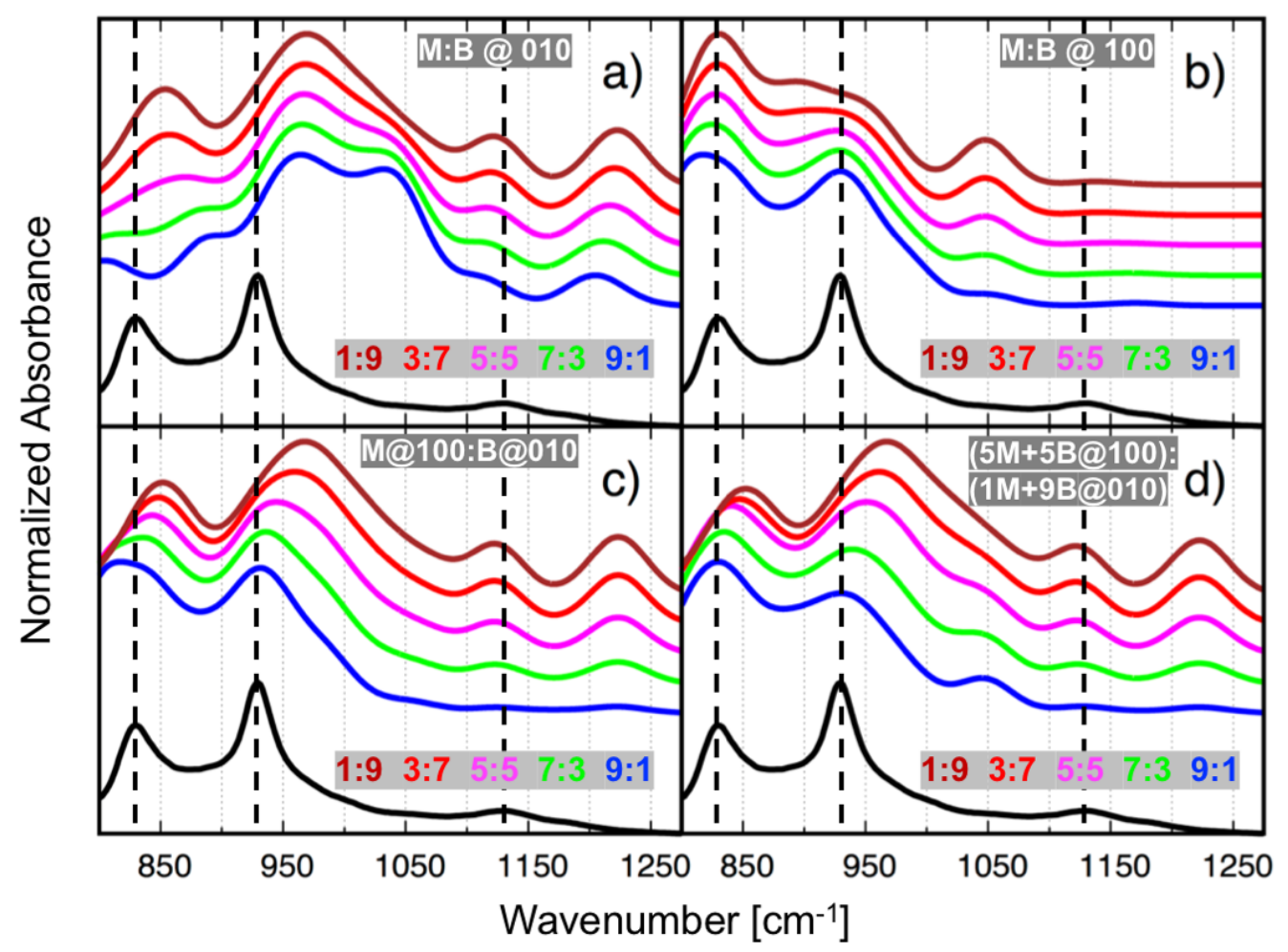

Fig. 7. Overall experimental IR spectrum (in blacke) versus weighted average spectra that are obtained via different combinations of the calculated overall spectra with different proportions of $\mathbf{M @ 0 1 0 ~ a n d ~ B @ 0 1 0 ~ b i n d i n g ~ m o t i f s ~ a ) , ~}$ M@100 and B@100 binding motifs b), M@100 and B@010 binding motifs c), 5 M@100 + 5 B@100 binding motifs and 1 M@010 + 9 B@010 binding motifs d). 


\section{Summary and Conclusions}

The present study introduced a combination of kinetics of phosphate adsorption on goethite, FT-IR, and periodic DFT calculations that is well-suited to draw a molecular-level picture about the phosphate binding mechanism at the goethite-water interface. The individual intermolecular interactions (i.e. between each two subsystems including phosphate and goethite, phosphate and water, and goethite and water) for the adsorbed phosphate at the goethite-water interface have been investigated and quantified here for the first time. Based on the structures of different binding motifs, a detailed analysis of their IR spectra has been presented and compared to experimental data. Further, it has been shown how the composition of the sample could influence the measured IR spectra. Although this rather pointed to the known difficulty of using IR spectroscopy as a marker for identification of binding motifs, the way of analysis could prove helpful for future investigations. The specific results are summarized in the following.

Phosphate $\left(\mathrm{KH}_{2} \mathrm{PO}_{4}\right.$ species) interacts with both goethite surface planes (010 and 100$)$ forming two different complexes ( $\mathbf{M}$ and $\mathbf{B}$ ) at each surface plane. For each phosphategoethite complex, one proton was found to be transferred from phosphate to water. For all cases, the interfacial water molecules formed HBs with phosphate as well as with the goethite surface. These water molecules approached the surface forming covalent bonds, through water $\mathrm{O}$ atoms, with goethite $\mathrm{Fe}$ atoms. Moreover, some water molecules were dissociated at the surface to protons and hydroxyl groups that transferred to the surface forming covalent bond with the goethite surface. All these observations indicate to very strong interaction not only between phosphate and goethite surface but also between water and goethite and between phosphate and water. This demonstrates the crucial role of water in controlling the phosphate adsorption process at the goethite surfaces.

Phosphate and water compete with each other at the goethite surface since both of them could be chemically adsorbed through formation of covalent bonds. At both goethite surface planes, the competition among phosphate, water, and the $\mathrm{OH}^{-}$group has been explored to find an increasing importance of the adsorption process in the order $\mathrm{H}_{2} \mathrm{O}<$ phosphate $<\mathrm{OH}^{-}$ . Based on this observation, one can conclude that phosphate can replace the adsorbed water molecules at the goethite surface but the $\mathrm{OH}^{-}$groups can replace both phosphate and water. This can explain, at a molecular-level, why the phosphate adsorption decreases with increasing the $\mathrm{pH}$ as observed experimentally.

At low phosphate loading and predominance of the $\mathrm{H}_{2} \mathrm{PO}_{4}{ }^{-}$species, the calculated interaction energies indicate a predominance of the mono-protonated bidentate binding motif for phosphates at the goethite-water interface with the possibility of a minor fraction of monodentate species. 
Correlating this result with features in IR spectrum is not straightforward. If an attempt is made to assign the current and previously reported experimental IR spectra in terms of individual binding motifs, the following can be concluded: (i) peaks around 1032 and $1050 \mathrm{~cm}^{-}$

1 are related to B@010 and $\mathbf{M} @ 100$ motifs, respectively, (ii) the peak around $927 \mathrm{~cm}^{-1}$ could come from the motifs M@010, B@010, and M@100, (iii) the peak around $827 \mathrm{~cm}^{-1}$ could stem from all considered motifs, and (iv) the interaction with goethite is most dominant in the range below $1000 \mathrm{~cm}^{-1}$. Taking the overall experimental spectrum as a reference, we found that spectra of the B@010 and M@100 complexes are in reasonable agreement with the experimental data. Still, an improvement could be achieved by taking weighted averages of spectra due to different motifs. Here, it was concluded that a ratio between $\mathbf{M}$ and $\mathbf{B}$ motifs of $1: 8$ performs best, regardless of the surface plane. In this respect, it is important to emphasize that the rather different IR intensities of the different motifs cannot be ignored in the analysis. The conclusion drawn from the IR spectrum confirms the interaction energy calculations according to which the mono-protonated $\mathbf{B}$ motifs are the dominant species and $\mathbf{M}$ exists as a minor fraction only.

\section{Conflicts of interest}

There are no conflicts to declare.

\section{Acknowledgement}

This work belongs to the InnoSoilPhos-project, funded by the German Federal Ministry of Education and Research (BMBF) in the frame of the BonaRes-program (No. 031A558). This research was performed within the scope of the Leibniz ScienceCampus "Phosphorus Research" Rostock. Furthermore, we thank Dr. A. Schleicher (Helmholtz Center Potsdam, German Research Centre for Geosciences GFZ, Telegrafenberg, 14473 Potsdam, Germany) for supporting XRD-measurements and analysis. The authors thank the North German Supercomputing Alliance for providing HPC resources (project mvp00016). 


\section{References}

[1] D. Cordell, J.-O. Drangert, S. White, The story of phosphorus: Global food security and food for thought, Glob. Environ. Change. 19 (2009) 292-305.

[2] J.D. Edixhoven, J. Gupta, H.H.G. Savenije, Recent revisions of phosphate rock reserves and resources: reassuring or misleading? An in-depth literature review of global estimates of phosphate rock reserves and resources, Earth Syst. Dyn. Discuss. 4 (2013) 1005-1034.

[3] M. Obersteiner, J. Peñuelas, P. Ciais, M. van der Velde, I.A. Janssens, The phosphorus trilemma, Nat. Geosci. 6 (2013) 897-898.

[4] J. Kruse, M. Abraham, W. Amelung, C. Baum, R. Bol, O. Kühn, H. Lewandowski, J. Niederberger, Y. Oelmann, C. Rüger, J. Santner, M. Siebers, N. Siebers, M. Spohn, J. Vestergren, A. Vogts, P. Leinweber, Innovative methods in soil phosphorus research: A review, J. Plant Nutr. Soil Sci. 178 (2015) 43-88.

[5] Y. Arai, D.L. Sparks, Phosphate Reaction Dynamics in Soils and Soil Components: A Multiscale Approach, in: Adv. Agron., Elsevier, 2007: pp. 135-179.

[6] Y. Arai, D.L. Sparks, ATR-FTIR Spectroscopic Investigation on Phosphate Adsorption Mechanisms at the Ferrihydrite-Water Interface, J. Colloid Interface Sci. 241 (2001) 317-326.

[7] N.J. Barrow, A mechanistic model for describing the sorption and desorption of phosphate by soil, J. Soil Sci. 34 (1983) 733-750.

[8] R. Chitrakar, S. Tezuka, A. Sonoda, K. Sakane, K. Ooi, T. Hirotsu, Phosphate adsorption on synthetic goethite and akaganeite, J. Colloid Interface Sci. 298 (2006) 602-608.

[9] P. Hinsinger, Bioavailability of soil inorganic $P$ in the rhizosphere as affected by root-induced chemical changes: a review, Plant Soil. 237 (2001) 173-195.

[10] J. Torrent, U. Schwertmann, V. Barron, Fast and slow phosphate sorption by goethite-rich natural materials, Clays Clay Miner. 40 (1992) 14-21.

[11] C. Luengo, M. Brigante, J. Antelo, M. Avena, Kinetics of phosphate adsorption on goethite: comparing batch adsorption and ATR-IR measurements, J. Colloid Interface Sci. 300 (2006) 511-518.

[12] J. McLaughlin, J. Ryden, J. Syers, Development and evaluation of a kinetic model to describe phosphate sorption by hydrous ferric oxide gel, Geoderma. 18 (1977) 295-307.

[13] I.R. Willett, C.J. Chartres, T.T. Nguyen, Migration of phosphate into aggregated particles of ferrihydrite, J. Soil Sci. 39 (1988) 275-282.

[14] J. Torrent, Interactions between phosphate and iron oxide, in: Soils Environ., Catena Verlag, Reiskirchen, Germany, 1997: pp. 321-344.

[15] S. Goldberg, G. Sposito, On the mechanism of specific phosphate adsorption by hydroxylated mineral surfaces: A review, Commun. Soil Sci. Plant Anal. 16 (1985) 801-821.

[16] R.L. Parfitt, Anion Adsorption by Soils and Soil Materials, in: Adv. Agron., Elsevier, 1979: pp. 1-50.

[17] J.D. Kubicki, K.W. Paul, L. Kabalan, Q. Zhu, M.K. Mrozik, M. Aryanpour, A.-M. Pierre-Louis, D.R. Strongin, ATR-FTIR and Density Functional Theory Study of the Structures, Energetics, and Vibrational Spectra of Phosphate Adsorbed onto Goethite, Langmuir. 28 (2012) 14573-14587.

[18] R.L. Parfitt, Phosphate reactions with natural allophane, ferrihydrite and goethite, J. Soil Sci. 40 (1989) 359-369.

[19] P. Persson, N. Nilsson, S. Sjöberg, Structure and Bonding of Orthophosphate lons at the Iron OxideAqueous Interface, J. Colloid Interface Sci. 177 (1996) 263-275.

[20] R. Strauss, G.W. Brummer, N.J. Barrow, Effects of crystallinity of goethite: II. Rates of sorption and desorption of phosphate, Eur. J. Soil Sci. 48 (1997) 101-114.

[21] A.C. Chapman, L.E. Thirlwell, Spectra of phosphorus compounds-I the infra-red spectra of orthophosphates, Spectrochim. Acta. 20 (1964) 937-947.

[22] M.I. Tejedor-Tejedor, M.A. Anderson, The protonation of phosphate on the surface of goethite as studied by CIR-FTIR and electrophoretic mobility, Langmuir. 6 (1990) 602-611.

[23] M. Villalobos, M.A. Cheney, J. Alcaraz-Cienfuegos, Goethite surface reactivity: II. A microscopic sitedensity model that describes its surface area-normalized variability, J. Colloid Interface Sci. 336 (2009) 
412-422.

[24] J.S. Loring, M.H. Sandström, K. Norén, P. Persson, Rethinking Arsenate Coordination at the Surface of Goethite, Chem. - Eur. J. 15 (2009) 5063-5072.

[25] K.D. Kwon, J.D. Kubicki, Molecular Orbital Theory Study on Surface Complex Structures of Phosphates to Iron Hydroxides: Calculation of Vibrational Frequencies and Adsorption Energies, Langmuir. 20 (2004) 9249-9254.

[26] J.D. Kubicki, K.D. Kwon, K.W. Paul, D.L. Sparks, Surface complex structures modelled with quantum chemical calculations: carbonate, phosphate, sulphate, arsenate and arsenite, Eur. J. Soil Sci. 58 (2007) 932-944.

[27] J.D. Martin, XPowder: A software package for qualitative and quantitative powder x-ray diffraction analysis, 2016. http://www.xpowder.com/.

[28] O.K. Borggaard, Effect of Surface Area and Mineralogy of Iron Oxides on Their Surface Charge and Anion-Adsorption Properties, Clays Clay Miner. 31 (1983) 230-232.

[29] D. Freese, P.G. Weidler, D. Grolimund, H. Sticher, A Flow-Through Reactor with an Infinite Sink for Monitoring Desorption Processes, J. Environ. Qual. 28 (1999) 537.

[30] J. Murphy, J.P. Riley, A modified single solution method for the determination of phosphate in natural waters, Anal. Chim. Acta. 27 (1962) 31-36.

[31] F. Xiu, L. Zhou, S. Xia, L. Yu, Adsorption mechanism of water molecule on goethite (010) surface, J. Ocean Univ. China. 15 (2016) 1021-1026.

[32] H. Guo, A.S. Barnard, Thermodynamic modelling of nanomorphologies of hematite and goethite, J. Mater. Chem. 21 (2011) 11566.

[33] J. Rakovan, U. Becker, M.F. Hochella, Aspects of goethite surface microtopography, structure, chemistry, and reactivity, Am. Mineral. 84 (1999) 884-894.

[34] R.M. Cornell, U. Schwertmann, The iron oxides: structure, properties, reactions, occurrences, and uses, 2nd, completely rev. and extended ed ed., Wiley-VCH, Weinheim, 2003.

[35] K.W. Paul, J.D. Kubicki, D.L. Sparks, Sulphate adsorption at the Fe (hydr)oxide-H2O interface: comparison of cluster and periodic slab DFT predictions, Eur. J. Soil Sci. 58 (2007) 978-988.

[36] J.D. Kubicki, K.W. Paul, D.L. Sparks, Periodic density functional theory calculations of bulk and the (010) surface of goethite, Geochem. Trans. 9 (2008) 4.

[37] J.D. Kubicki, D. Tunega, S. Kraemer, A density functional theory investigation of oxalate and $\mathrm{Fe}(\mathrm{II})$ adsorption onto the (010) goethite surface with implications for ligand- and reduction-promoted dissolution, Chem. Geol. 464 (2017) 14-22.

[38] A. Szytuła, A. Burewicz, ž. Dimitrijević, S. Kraśnicki, H. Rżany, J. Todorović, A. Wanic, W. Wolski, Neutron Diffraction Studies of a-FeOOH, Phys. Status Solidi B. 26 (1968) 429-434.

[39] A.A. Ahmed, P. Leinweber, O. Kühn, Unravelling the nature of glyphosate binding to goethite surfaces by ab initio molecular dynamics simulations, Phys. Chem. Chem. Phys. 20 (2018) 1531-1539.

[40] L. Martínez, R. Andrade, E.G. Birgin, J.M. Martínez, PACKMOL: A package for building initial configurations for molecular dynamics simulations, J. Comput. Chem. 30 (2009) 2157-2164.

[41] J. VandeVondele, M. Krack, F. Mohamed, M. Parrinello, T. Chassaing, J. Hutter, Quickstep: Fast and accurate density functional calculations using a mixed Gaussian and plane waves approach, Comput. Phys. Commun. 167 (2005) 103-128.

[42] J. Hutter, M. Iannuzzi, F. Schiffmann, J. VandeVondele, CP2K: Atomistic Simulations of Condensed Matter Systems, Wiley Interdiscip. Rev. Comput. Mol. Sci. 4 (2014) 15-25.

[43] B.G. Lippert, J.H. and M. Parrinello, A hybrid Gaussian and plane wave density functional scheme, Mol. Phys. 92 (1997) 477-488.

[44] J.P. Perdew, K. Burke, M. Ernzerhof, Generalized Gradient Approximation Made Simple, Phys. Rev. Lett. 77 (1996) 3865-3868.

[45] M. Krack, Pseudopotentials for $\mathrm{H}$ to $\mathrm{Kr}$ optimized for gradient-corrected exchange-correlation functionals, Theor. Chem. Acc. 114 (2005) 145-152.

[46] J. VandeVondele, J. Hutter, Gaussian basis sets for accurate calculations on molecular systems in gas and condensed phases, J. Chem. Phys. 127 (2007) 114105. 
[47] S. Grimme, S. Ehrlich, L. Goerigk, Effect of the damping function in dispersion corrected density functional theory, J. Comput. Chem. 32 (2011) 1456-1465.

[48] H.B. Jansen, P. Ros, Non-empirical molecular orbital calculations on the protonation of carbon monoxide, Chem. Phys. Lett. 3 (1969) 140-143.

[49] I.M. Alecu, J. Zheng, Y. Zhao, D.G. Truhlar, Computational Thermochemistry: Scale Factor Databases and Scale Factors for Vibrational Frequencies Obtained from Electronic Model Chemistries, J. Chem. Theory Comput. 6 (2010) 2872-2887.

[50] C. Shang, J.W.B. Stewart, P.M. Huang, pH effect on kinetics of adsorption of organic and inorganic phosphates by short-range ordered aluminum and iron precipitates, Geoderma. 53 (1992) 1-14.

[51] M. Talebi Atouei, R. Rahnemaie, E. Goli Kalanpa, M.H. Davoodi, Competitive adsorption of magnesium and calcium with phosphate at the goethite water interface: Kinetics, equilibrium and CD-MUSIC modeling, Chem. Geol. 437 (2016) 19-29.

[52] L. Krumina, J.P.L. Kenney, J.S. Loring, P. Persson, Desorption mechanisms of phosphate from ferrihydrite and goethite surfaces, Chem. Geol. 427 (2016) 54-64.

[53] M. Nanzyo, Infrared Spectra of Phosphate Sorbed on Iron Hydroxide Gel and the Sorption Products, Soil Sci. Plant Nutr. 32 (1986) 51-58.

[54] T.-T. Zheng, Z.-X. Sun, X.-F. Yang, A. Holmgren, Sorption of phosphate onto mesoporous Y-alumina studied with in-situ ATR-FTIR spectroscopy, Chem. Cent. J. 6 (2012).

[55] R.J. Atkinson, R.L. Parfitt, R.S.C. Smart, Infra-red study of phosphate adsorption on goethite, J. Chem. Soc. Faraday Trans. 1 Phys. Chem. Condens. Phases. 70 (1974) 1472.

[56] F. Liu, A. De Cristofaro, A. Violante, Effect of pH, phosphate and oxalate on the adsorption/desorption of arsenate on/from goethite, Soil Sci. 166 (2001).

[57] J. Antelo, M. Avena, S. Fiol, R. López, F. Arce, Effects of pH and ionic strength on the adsorption of phosphate and arsenate at the goethite-water interface, J. Colloid Interface Sci. 285 (2005) 476-486. 


\section{Supplementary Information (SI)}

\section{Infrared Spectroscopic Characterization of Phosphate Binding at the Goethite-Water Interface}

Ashour A. Ahmed ${ }^{1,2, *}$, Stella Gypser ${ }^{3}$, Peter Leinweber ${ }^{2,4}$, Dirk Freese ${ }^{3}$, Oliver Kühn ${ }^{1,2}$

\footnotetext{
${ }^{1}$ University of Rostock, Institute of Physics, Albert-Einstein-Str. 23-24, D-18059 Rostock, Germany.

${ }^{2}$ University of Rostock, Department of Life, Light, and Matter (LLM), Albert-Einstein-Str. 25, D-18059

Rostock, Germany

${ }^{3}$ Brandenburg University of Technology Cottbus-Senftenberg, Chair of Soil Protection and

Recultivation, Konrad-Wachsmann-Allee 6, 03046 Cottbus, Germany

${ }^{4}$ University of Rostock, Chair of Soil Science, Justus-von-Liebig-Weg 6, D-18059 Rostock, Germany
}

\section{S1. Details about the interaction energy calculations}

In general, the effect of water on the phosphate-goethite interaction has been considered during the geometry optimization due to the water-phosphate-goethite interactions based on the electronic and Van der Waals interactions. However, this effect has not been considered explicitly for computing the interaction energy in Eq. 1. In practice, each phosphate-goethite-water model could be considered as three sub-systems (fragments). These fragments are phosphate (fragment1), goethite (fragment2), and water (fragment3). Within $\mathrm{CP} 2 \mathrm{~K}$ it is possible to calculate the pair interaction energy between two fragments. According to Eq. 1 ( $\left.E_{\text {int }}=E_{\text {phosphate-goethite-complex }}-\left(E_{\text {phosphate }}+E_{\text {goethite surface }}\right)\right)$, we have defined phosphate as the first fragment and goethite as the second fragment. Water enters only insofar as it determines the actual geometry of the interacting fragments. The interaction energy is calculated within the BSSE counterpoise correction philosophy, i.e. by performing five energy calculations as follows: total electronic energy of phosphate including only the phosphate basis functions ( $E_{\text {phosphate }}^{\text {phosphate }}$, goethite including only the goethite basis functions 
$\left(E_{\text {goethite }}^{\text {goethite }}\right)$, phosphate including the basis functions of phosphate and goethite $\left(E_{\text {phosphate }}^{\text {phosphate }}\right.$ goethite $)$, goethite including the basis functions of phosphate and goethite $\left(E_{\text {goethite }}^{\text {phosphate }+ \text { goethite }}\right)$, and finally phosphate-goethite complex including the basis functions of phosphate and goethite $\left(E_{\text {phosphate-goethite-complex }}^{\text {phosphate }}\right)$ From these numbers one gets the interaction energy between phosphate and goethite as $E_{\text {int }}=E_{\text {phosphate-goethite-complex }}^{\text {phosphate }}$ $\left(E_{\text {phosphate }}^{\text {phosphate }+ \text { goethite }}+E_{\text {goethite }}^{\text {phosphate }+ \text { goethite }}\right)$. Similarly, the interaction energies between phosphate and water $\left(E_{\text {int }}=E_{\text {phosphate-water-complex }}^{\text {phosphate+water }}-\left(E_{\text {phosphate }}^{\text {phosphater }}+E_{\text {water }}^{\text {phosphate+water }}\right)\right)$ and between goethite and water $\left(E_{\text {int }}=E_{\text {goethite-water-complex }}^{\text {goethite }+ \text { water }}-\left(E_{\text {goethite }}^{\text {goethite }}+\right.\right.$ $\left.E_{\text {water }}^{\text {goethite+water }}\right)$ ) could be calculated.

\section{S2. X-ray diffraction data}

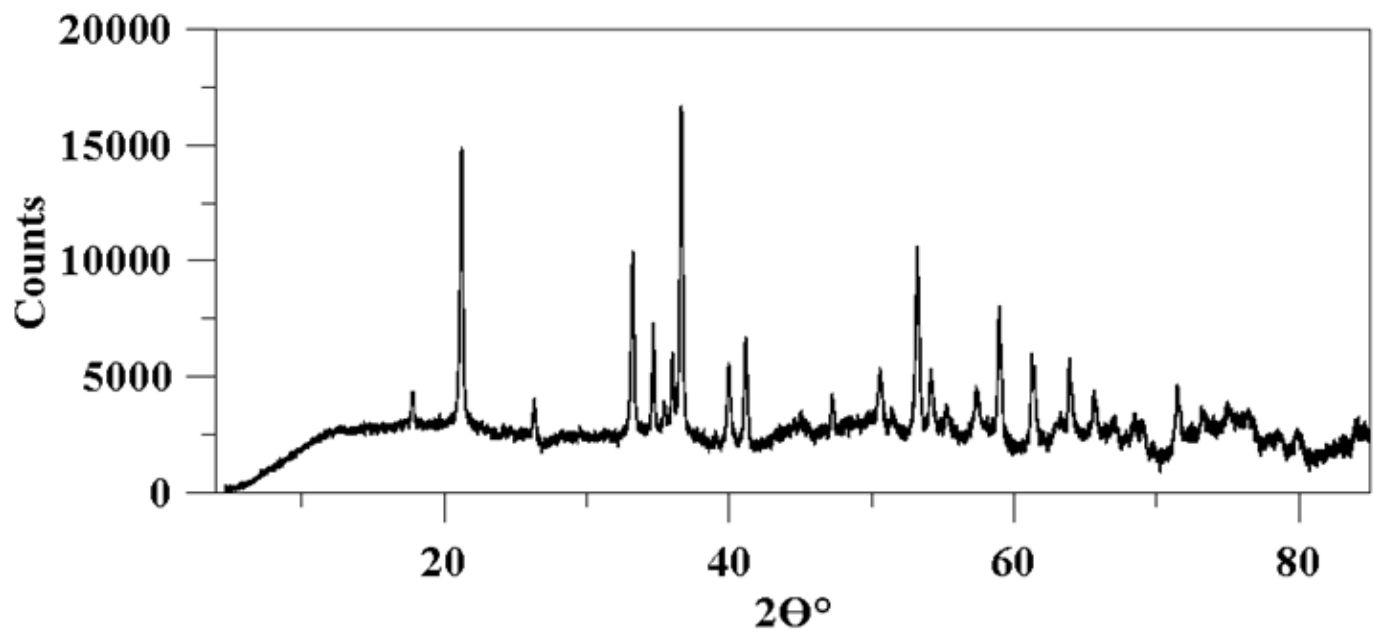

Fig. S1. X-ray diffraction pattern of the synthetic goethite sample used in this study (lattice parameters: $a=4.61 \AA$, $b=9.96 \AA$, and $c=3.02 \AA$ ). 


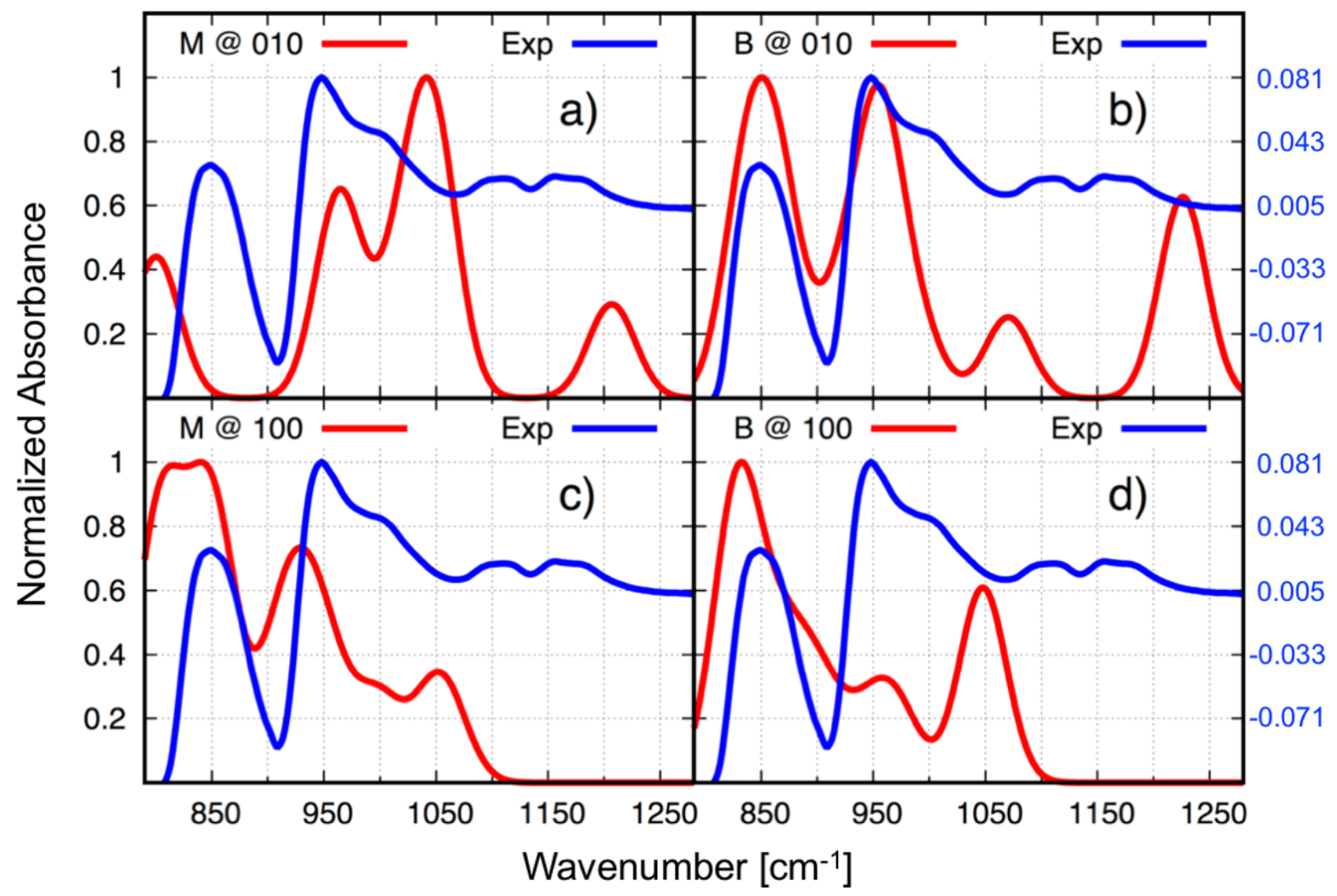

Fig. S2. Experimental difference IR spectrum relevant to the P-goethite complex (in blue, compare Fig. 2) versus the phosphate-related spectra calculated for M@010 a), B@010 b), M@100 c), and B@100 d) in the range of 800$1300 \mathrm{~cm}^{-1}$. The original scale for the experimental spectrum was added to the right axis in blue.

Figure S2 shows that the IR spectrum for the B@010 complex (Fig. S2b) is closest to the experimental IR spectrum compared to the other calculated spectra. This holds specifically for the first two IR spectral features, i.e. in the spectral range of $800-1000 \mathrm{~cm}^{-1}$. Here, it is important to mention that the first feature observed around $850 \mathrm{~cm}^{-1}$ for the B@010 complex involves $2 \mathrm{O}_{\mathrm{b}}-\mathrm{P}-2 \mathrm{O}_{\mathrm{nb}}$ symmetric stretching and $\mathrm{P}-\mathrm{O}-\mathrm{H}$ bending vibrations. The second observed feature around $945 \mathrm{~cm}^{-1}$ for the same complex corresponds mainly to $2 \mathrm{O}_{b}-\mathrm{P}-\mathrm{O}_{\mathrm{nb} 2}$ symmetric stretching and $\mathrm{O}_{\mathrm{b} 2}-\mathrm{P}-\mathrm{O}_{\mathrm{nb} 1}$ asymmetric stretching vibrations. Moreover, the IR spectrum for the M@100 complex is also close to the experimental IR spectrum (see Fig. S2c). Here, the first feature seems as a bimodal peak with a local maximum, around $840 \mathrm{~cm}^{-}$ ${ }^{1}$, closer to the experimental feature that corresponds to $\mathrm{P}-2 \mathrm{O}_{\mathrm{nb}}$ stretching and bending vibrations. Furthermore, the second feature observed around $930 \mathrm{~cm}^{-1}$ is due to $\mathrm{P}-\mathrm{O}_{\mathrm{b}}$ stretching, $\mathrm{P}-\mathrm{O}_{\mathrm{nb} 1}$ stretching, $\mathrm{O}_{\mathrm{b}}-\mathrm{P}-2 \mathrm{O}_{\mathrm{nb} 1,2}$ symmetric stretching, $\mathrm{P}-3 \mathrm{O}_{\mathrm{nb}}$ asymmetric stretching, and $\mathrm{O}_{b}-\mathrm{P}-2 \mathrm{O}_{\mathrm{nb} 2,3}$ asymmetric stretching vibrations. For the M@010 complex (see Fig. S2b), and the B@100 complex, (see Fig. S2d), one observes a larger deviation in the position for the first two features compared to the experimental ones especially for the first 
feature. The first two features in the spectrum of the $\mathbf{M @ 0 1 0 ~ c o m p l e x ~ a r e ~ a t ~} 800$ and $965 \mathrm{~cm}^{-}$ ${ }^{1}$ and are due to $\mathrm{P}-3 \mathrm{O}_{\mathrm{nb}}$ complex vibration and $\mathrm{O}_{\mathrm{b}}-\mathrm{P}-2 \mathrm{O}_{\mathrm{nb} 1,3}$ symmetric stretching vibration, respectively, in addition to $\mathrm{P}-\mathrm{O}-\mathrm{H}$ bending vibration. For the $\mathrm{B} @ 100$ complex, the first two features existed around 830 and $960 \mathrm{~cm}^{-1}$. The first feature involved an $\mathrm{O}_{\mathrm{b} 2}-\mathrm{P}-2 \mathrm{O}_{\mathrm{nb}}$ symmetric stretching vibration while the second one involved $\mathrm{P}-\mathrm{O}_{\mathrm{nb} 1}$ stretching, $\mathrm{O}_{\mathrm{b} 2}-\mathrm{P}-\mathrm{O}_{\mathrm{nb} 1}$ antisymmetric stretching, and $\mathrm{P}-\mathrm{O}-\mathrm{H}$ bending vibrations. For the latter two complexes, the shape of the calculated spectra in the range of $800-1000 \mathrm{~cm}^{-1}$ is somehow different than the experimental one. This also confirms that spectra of both B@010 and M@100 complexes are closer to the experimental spectrum than the other two complexes. 